\title{
Safeguarding and using global banana diversity: a holistic approach
}

\author{
Ines Van den houwe ${ }^{1}$, Rachel Chase², Julie Sardos², Max Ruas², Els Kempenaers ${ }^{3}$, Valentin Guignon², \\ Sebastien Massart ${ }^{4}$, Sebastien Carpentier ${ }^{1}$, Bart Panis ${ }^{1}$, Mathieu Rouard ${ }^{2}$ and Nicolas Roux ${ }^{2^{*}}$
}

\begin{abstract}
The CGIAR genebank International Musa Germplasm Transit Centre (ITC) currently holds 1617 banana accessions from 38 countries as an in vitro collection, backed-up by a cryopreserved collection to safeguard global Musa diversity in perpetuity. The ITC also serves as a vital safety backup and transit centre for national banana genebanks and ensures that germplasm is clean of pests and diseases and freely available under the International Treaty on Plant Genetic Resources for Food and Agriculture. In more than 35 years of activity, the ITC has distributed over 18,000 banana accession samples to researchers and farmers in 113 countries. Ex situ conservation of vegetatively-propagated crops such as banana poses very particular challenges. Maintaining the ITC genebank is labor intense and costly. Efficiencies are sought through research and development of techniques on detecting viruses, the genetic integrity of accessions, and on innovative means of safeguarding banana diversity, such as conserving populations of wild species by seed banking. Although the conservation of global banana diversity is the main objective of the ITC, significant value comes from its holistic approach to better understand and promote its germplasm through numerous research activities and resources. Techniques for morphological and molecular characterization serve to identify and describe the collection, while also determining what gaps should be filled by collecting missions with national partners. The evaluation of desirable agronomic traits inherent in Musa spp. are investigated by a high-throughput phenotyping platform, which helps breeding programs to select cultivars resistant or tolerant to biotic and abiotic stresses. Genomic and bioinformatic studies of several banana wild relatives greatly enhance our understanding of Musa genetic diversity, links to important phenotypic traits and bring new methods for management of the collection. Collectively, these research activities produce enormous amounts of data that require curation and dissemination to the public. The two information systems at the ITC, Musa Genebank Management System and the Musa Germplasm Information System, serve to manage the genebank activities and to make public germplasm-related data for over 30 banana collections worldwide, respectively. By implementing the 10-year workplan set out in the Global Strategy for the Conservation and Use of Musa Genetic Resources, the network MusaNet supports Musa researchers and stakeholders, including the ITC, and most importantly, links to the world's banana-producing countries via three regional banana networks.
\end{abstract}

Keywords: Genebank, Banana, Vegetative propagation, Germplasm conservation, Phenotyping, Genomics, Information systems, Networks, Collecting missions, Crop diversity

*Correspondence: n.roux@cgiar.org

2 Bioversity International, Parc Scientifique Agropolis II, 34397 Montpellier, France

Full list of author information is available at the end of the article

\section{Introduction \\ International Musa Germplasm Transit Centre, a CGIAR international Genebank}

CGIAR genebanks conserve collections of plant genetic resources for food and agriculture and were placed under the auspices of Food and Agriculture Organization (FAO) commission on Plant Genetic Resources in 1994. Under 
the International Treaty on Plant Genetic Resources for Food and Agriculture (ITPGRFA, hereafter referred to as the International Treaty), these genebanks have to make their respective germplasm available under the terms of a Standard Material Transfer Agreement and manage their collections following the highest international agreed standards. Taken together, CGIAR genebanks represent the largest collections of crop diversity in the world. With nearly 1 million germplasm samples distributed between 1985 and 2009, they are a key resource for plant breeding and research (Galluzzi et al. 2016). Since 2012, the CGIAR genebanks are working as partners within the Genebank Platform, coordinated by the Global Crop Diversity Trust, to help them reach the United Nations Sustainable Development Goals.

In addition, to comply with the highest standards, the CGIAR genebanks have adopted targets to assure that by 2022, 90\% of the conserved accessions are readily available for distribution; $90 \%$ of the accessions are safely duplicated; $90 \%$ of the accessions display minimum passport or characterization data online and standard operating procedures are in place for the genebanks "essential operations." ${ }^{1}$ Through the Genebank Platform, the Crop Trust has put in place an endowment mechanism to ensure that the genebanks can carry out those essential operations. To date, the targeted endowment is still being built and the CGIAR is currently still complementing it. Other activities which allow to upgrade the collection or improve the use of germplasm are being funded by other CGIAR Research programs. In the case of ITC, other funding is through the Roots, Tubers and Bananas CGIAR program.

Among the 11 CGIAR genebanks, four deal with the conservation of vegetatively-propagated crops. These crops, the Andean root and tuber crops, banana, cassava, potato, sweet potato and yam, are conserved in field and in vitro collections. The combination of their clonal nature and of the specific technologies used for their conservation results in very specific challenges. Consequently, the four responsible centres, Bioversity International, the International Centre for Tropical Agriculture (CIAT), the International Potato Centre (CIP) and the International Institute for Tropical Agriculture (IITA) have formed a 'Clonal Crop Community of Practice' that aims to provide solutions and recommendations to deal with these specific issues.

The International Musa Germplasm Transit Centre (ITC) holds 'in trust' the world largest collection of banana. As banana is an Annex 1 crop of the

\footnotetext{
${ }^{1}$ The "essential operations" of a genebank are the minimum activities that must be undertaken without which the security of the collections and their use are at risk.
}

International Treaty, the ITC collection became part of the multilateral system of access and benefit sharing in 2006. Founded in 1985 and hosted at the Katholieke Universiteit Leuven, Belgium, the genebank's mission is to contribute to the secure long-term conservation of the entire banana genepool and to keep this diversity and related information available for current and future use. Beyond that, the ITC's role is to add value to the collection by generating new knowledge about the conserved diversity through characterization, phenotyping, genomics, bioinformatics and documenting it comprehensively in accession-level information systems.

The ITC benefits from the newest technologies, such as cryopreservation and high-throughput phenotyping and has built a team with expertise in these fields of research. In addition, the genebank is named 'International Transit Centre' as it is located in a non-banana growing country, Belgium, where pest and diseases associated with banana do not occur, allowing germplasm to be easily distributed and received without major phytosanitary constraints. At the global level, the ITC collection functions effectively by assuring medium and long-term conservation of the broadest range of Musa diversity. ITC has strong relationships with regional and national collections in Asia and the Pacific, Africa and Latin America and the Caribbean, who donate their germplasm to the global system, while ITC provides these collections with clean material and safety backups of their germplasm. The ITC also collaborates with these partner collections in terms of research and capacity building in conservation methods. Unlike other centres linked to their own breeding program, the ITC genebank serves several international and national breeding programs on banana.

\section{Global strategy for the conservation and use of Musa genetic resources}

A Global Musa Survey was conducted between 2012 and 2015, in which over 50 banana germplasm collections worldwide provided information on their status and needs. Capitalizing on the survey, in 2016 MusaNet published the Global Strategy for the Conservation and Use of Musa Genetic Resources (MusaNet 2016), the core reference and roadmap for the banana community over the next 10 years. The vision of the Global Musa Strategy is a world in which Musa genetic diversity is secured, valued and used to support livelihoods of hundreds of millions of farmers through sustainable production and improved food and nutrition security (de Langhe et al. 2018).

The Global Musa Strategy outlined the following main challenges concerning the ITC: 


\section{Challenges linked to conservation}

The storage of banana germplasm for the medium-term (active collection) is done in vitro which represents great advantages but also some challenges such as relatively high maintenance costs, possible genetic integrity issues and difficulties keeping some genotypes free of the banana streak virus. The long-term storage (base collection) is done through cryopreservation, which resolves some of the issues encountered with the in vitro collection, but also faces some other challenges. For example, cryopreservation is costly to put in place, but cheaper in the long run (Keller et al. 2013). It is also relatively slow to implement and cannot be used for regular germplasm distribution.

\section{Challenges linked to use}

The most critical aspect to increasing use is a good documentation status of the conserved material. Although the exact identity of plant material is an obvious prerequisite for all users, data about both agronomic performance, such as productivity and resistance to pests and diseases, and quality, such as fruit flavor and processing characteristics, are critical in the selection of desired cultivars. The proportion of characterized material, especially evaluated accessions, is too low and thus limits its full potential. In addition, better understanding of the genetic background (through molecular markers and genomes) is needed to support breeding. However, the ITC has provided material in different forms that has contributed to increased use, for example, through the distribution of lyophilized leaves to molecular biologists. Additionally, if wild genotypes could be maintained and distributed through seeds, it would certainly increase its use, especially by breeders and researchers involved in evolution and domestication studies.

\section{Challenges linked to material access}

The ITC collection became part of the Multilateral System of Access and Benefit Sharing along with all the international collections. The exchange of germplasm occurs under the terms and conditions of a standard material transfer agreement (SMTA), which allows distribution of germplasm free of charge for research, breeding or conservation purposes only. The objective of the SMTA is to facilitate the process of safely exchanging and tracking use of germplasm and to encourage users to share any benefits from the use of the germplasm or resulting research products. In some cases, the acquisition of Musa germplasm by the ITC has been constrained by legal and policy issues mainly related to the International Treaty not yet being fully implemented in some countries. Acquisition may be difficult when countries are not a contracted party to the International Treaty, preventing access to the materials and related information for use or safe duplication elsewhere. However, the main challenge is where certain parties have not yet put their material in the public domain. This could be linked to the lack of clear communication on incentives to provide material.

\section{Conservation of germplasm \\ Active collection (medium-term storage) Collection holdings}

The ITC banana collection was established in 1985 and has since been through several phases of growth. Initially, duplicate samples of banana accessions maintained in major field collections were received by the genebank, thus securing these genetic resources in a different location using in vitro culture. Over the years, the exploitable genetic basis of the collection was further broadened by unique diversity that was collected in the (primary and secondary) centres of diversity of the crop. Over 400 accessions, mainly Musa acuminata spp. banksii derived AA landraces from Papua New Guinea (Sharrock 1988, 1989; Sharrock et al. 1988, 1989; Arnaud and Horry 1997), Mshare landraces from East Africa (Byabachwezi et al. 2005), diploid- and triploid A dessert types from Vietnam and Indonesia, Fe'i, AAB Pacific plantains from the Pacific Islands (Sardos et al. 2019a, b) and a range of phenotypically unique (dwarf-type) plantain cultivars from DR Congo (Adheka et al. 2018) were progressively brought into the ITC. As a result of the Global Diversity Crop Trust-coordinated project on the 'Regeneration and safety duplication of regionally prioritized crop collections', the ITC collection was further enriched with nearly 200 unique samples of cultivated and wild bananas from Cameroon, Vietnam, Indonesia, Uganda, India, and the Philippines. More recently, the focus of collecting is far more on wild species that are particularly vulnerable to extinction in their natural habitat and difficult to maintain in field collections, while in high demand for breeding activities to sustain banana production.

Today the collection holds 1617 accessions, sourced from 38 countries, mainly of cultivated bananas (75\%) belonging to 17 genome groups and 52 subgroups, a range of highly productive and disease resistant cultivars (9\%) developed by major banana breeding programs, and a representation of the wild genepool (16\%) with samples of 34 species. All these accessions are preserved in vitro in slow growth and nearly 1100 accessions are backedup in a cryopreserved state for their safe long-term conservation. 


\section{Slow growth storage at the ITC}

The management of in vitro plants under conditions for optimal growth is labor intensive due to the need for frequent subculturing, involving an increased risk of losing valuable germplasm through accidental contamination, mixing up varieties through mislabeling or changes in genotype through somaclonal variation. In general, in vitro genebanks establish minimal growth conditions to reduce the growth rate of the plant tissues and the frequency of subculturing.

Slow growth conditions are achieved by altering the chemical environment, i.e. changing the medium composition by adding osmotically active compounds, such as sucrose and mannitol or growth retardants such as paclobutrazol, or by reducing the concentration of mineral elements in the growth medium. Other minimal growth options are modification of the physical growth environment such as altering the gaseous environment in the culture container, a reduction of the photoperiod, light intensity or the characteristics of the tissue culture container.

The growth retarding factor that is most widely adopted for in vitro active banana collections is a reduction of the storage temperature. At the ITC, banana fresh shoot (tip) cultures are usually incubated pre-storage under normal growth conditions at an optimal temperature of $26 \pm 2{ }^{\circ} \mathrm{C}$ for 2 to 3 weeks. Of each accession, 20 replicate cultures are grown on an MS based medium, supplemented with two growth regulators, BA (6-benzyladenine) and IAA (indole-3-acetic acid) to stimulate multiple shoot development, 10 g.L $\mathrm{L}^{-1}$ ascorbic acid to suppress the oxidation of polyphenolic exudates of the tissues and 2 g.L. $\mathrm{L}^{-1}$ of the medium solidifying agent Gelrite. When established, the cultures are placed under slow growth conditions at a temperature of $16 \pm 1{ }^{\circ} \mathrm{C}$. In the storage room also the light (PPF) is reduced from $63 \mu \mathrm{E} . \mathrm{m}-2 . \mathrm{s}-1$ to $25 \mu \mathrm{E} . \mathrm{m}-2 . \mathrm{s}-1(24 \mathrm{~h})$.

Under these conditions, the storage duration of the collection is extended to nearly one year on average. While the conditions are standardized for all accessions in vitro, the frequency of subculturing varies significantly for the different genomic groups, subgroups and even for cultivars within the same genome subgroup. For example, the AAA Mutika Lujugira bananas from East Africa and $\mathrm{AAB}$ non-plantain bananas can be stored significantly longer, up to an average of 390 and 385 days respectively. Wild bananas, M. acuminata and in particular M. balbisiana require subculturing more frequently after a storage period of 275 days on average. Some individual accessions can be stored for a period up to 615 days (Lady Finger-Pome, AAB) whereas others require subculturing every 60 days (SF215, a AA $M$. acuminata sp. banksii derivative), showing also within one genomic group of bananas significant differences in storage behavior (Van den houwe et al. 1995).

Maintaining banana germplasm in vitro as growing plants has its advantages, but it must be recognized that the method is labor intense. Proper management of an in vitro collection to keep the collection alive and in good shape requires periodic checks for viability, vigor and deterioration to assess accurately culture growth and to determine the proper moment for subculturing of the plant material. Samples of the collection are also systematically tested at critical points in the conservation process (culture initiation and annual subculturing) for contamination to detect covert and systemic bacteria and to prevent the proliferation of microbes in the conserved germplasm that may interfere with the storage duration and use of the plant material (Van den houwe and Swennen 1999). As the vitality of tissue cultures also declines over the course of successive growth and storage cycles in vitro, old accessions in storage need to be rejuvenated in the greenhouse and replaced by fresh shoot-tip cultures. This renewal of material is carried out for accessions that have been maintained continuously in vitro for more than ten years.

The greatest risk however of in vitro storage of plant materials, is the increased possibility of genetic instability due to somaclonal variation. It is known that variations may increase with time in culture, ultimately resulting in the loss of genetic integrity of the genotype. Moreover, the problem is complex, as not only genetic but also epigenetic factors may be involved (Oh et al. 2007; Tarafdar et al. 2017). Trueness-to-type verification of in vitro conserved plant materials relies on morphological description, periodical field assessment and cytological characterization to assess and describe somaclonal variants (see section on field verification).

\section{Virus indexing}

Distributing healthy accessions has always been a top priority for the ITC collection. The applied protocol of in vitro culture allows the elimination of the cellular pathogens (bacteria and fungi). Nevertheless, viruses, as intracellular pathogens sometimes symptomless in the field and easily transferred from a mother plant to in vitro culture, need to be specifically tested. Viruses therefore pose a special risk to the movement of vegetative germplasm. The virus testing is particularly important as several banana growing countries are currently free of damaging viral diseases. The banana bunchy top virus is not present in South America while the banana bract mosaic virus is only present in some Asian countries, and the virus prevalence in collected germplasms reaches 68\% (De Clerck et al. 2017). Therefore, guaranteeing the movement of pathogen-tested germplasm is an 
important task to minimize the risk of pest introduction to new countries.

Noteworthy, banana streak viruses (BSVs) are a group of related badnaviruses which cause banana streak disease and pose a unique problem in Musa germplasm (Chabannes et al. 2013). Not only can they be present as episomal infections but functional viral genomes of some BSV species are also naturally integrated into the Musa balbisiana genome and are known as endogenous BSV (eBSV) sequences. Under certain stress conditions (e.g. during cross hybridization, tissue culture, or abiotic stress), some eBSVs can be activated and give rise to functional viral genomes that trigger BSV episomal infections (Iskra-Caruana et al. 2014). So, episomal infection from the integrated BSV genome could be triggered under specific and not well understood growth conditions.

The Germplasm Health Unit of the ITC collection is hosted at Liège University, Belgium, and is applying the most comprehensive testing scheme to detect infecting viruses in the germplasm. The Technical Guidelines for the Safe Movement of Musa germplasm are strictly followed (Thomas et al. 2015). Any tested accession is grown for 6 months in the greenhouse and is tested for viruses twice, at 3 and 6 months. The tests combine visual inspection for viral symptoms, molecular tests by PCR and electron microscopy. An accession becomes available if all the tests were negative. In the case of accessions with the integrated BSV genome, they are available under a disclaimer stating that BSV episomal infection can be triggered at any time, even for negative-tested accessions.

The accessions that have tested positive for a virus will undergo a sanitation process: thermotherapy and chemotherapy are combined with meristem culture to eliminate the infecting virus (Lassois et al. 2013). After therapy, the accession is tested again after 3 and 6 months of greenhouse growth and, if negative, can be available for distribution. Importantly, the success of sanitation is very variable depending on the accession's genetic makeup and the virus. Indeed, sanitation failure is repeatedly observed for some accessions because of plant death during the process or remaining infection by the virus. Adapted protocols are currently being designed to raise the success rate and the accession availability.

The Germplasm Health Unit is also continuously exploring improvement of the diagnostic tests to ensure the safest and quickest possible distribution of the germplasm. For example, the Germplasm Health Unit is currently at the forefront of the development of High Throughput Sequencing technologies as a universal diagnostic test for accurate and sensitive detection of plant viruses (Massart et al. 2017; Olmos et al. 2018) and these technologies are already used to detect new viral species or very distant isolates of known viruses infecting Musa germplasm. Their wider use in routine testing is currently being tested at large scale.

\section{Germplasm distribution and use}

Besides its conservation role, the ITC is a facilitator of the exchange of clean and healthy germplasm. An important constraint to germplasm use in general is the difficulty to physically access materials from collections. Often, phytosanitary and legal restrictions on access pose barriers for the movement of germplasm.

To meet the needs for research and of the breeding community, the ITC distributes samples from its active in vitro collection (i.e. rooted plants suitable for growing in a nursery or multiple shoot clusters for further in vitro propagation or studies). With the advances in genetics and genomics in the last two decades and in order to enhance the use of the stored diversity, a lyophilized leaf tissue collection of freeze-dried leaf tissue derived from indexed plants of over 800 accessions was established in 2006, serving as a low-cost alternative compared to living plant material for researchers interested in using the DNA only.

Since its foundation, the ITC has distributed over 18,000 banana accession samples to users in 113 countries, indicating that the long-term conservation of the diversity is highly valued throughout the community of banana researchers (Fig. 1). Germplasm from the ITC mainly flows to National Agricultural Research Systems (62\%) in developing countries where bananas are an essential crop for subsistence agriculture or the local market. The remaining 38\% is destined for advanced research institutes and universities in developed countries. Further analysis of the distribution records revealed that annually an average of $30 \%$ of the available accessions are accessed for use, showing great interest from users for exploiting the diversity of the crop. Nearly twothirds of the requested germplasm concerns cultivated forms, landraces of local importance and cultivars that are mainly intended for traits evaluation, such as biotic (Fusarium wilt, Black Sigatoka, Banana Xanthomonas Wilt, nematodes and weevils), abiotic (wind, drought, flooding, salinity) stress tolerance and agronomic traits (yield and fruit quality). Improved cultivars from breeding activities are requested for their superior yield and disease resistance characteristics and account for $20 \%$ of the distributed materials, while $17 \%$ of the disseminated germplasm are wild species, serving as a source of potential valuable genes in breeding activities and for taxonomic and phylogenetic studies.

Although it is difficult to trace back how the germplasm is used and what benefits have been created from the utilization of the distributed diversity, surveyed recipients of the germplasm indicated that the uses of the supplied 


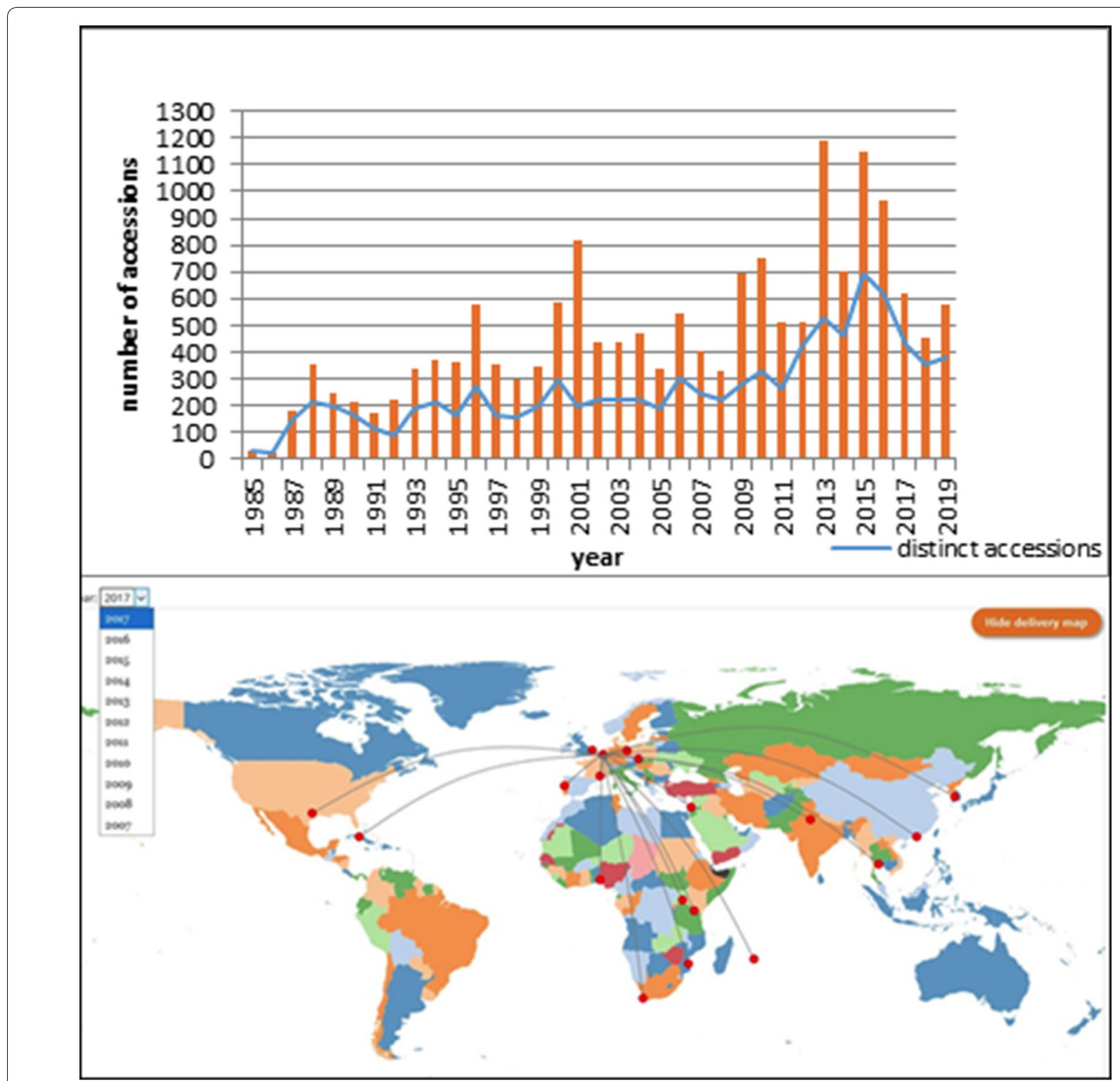

Fig. 1 Annual numbers of distributed germplasm samples and of distinct accessions from the ITC showing the increasing use and interest in diversity. The map shows the global extent of germplasm recipients

diversity are multiple, including research, education, conservation, breeding and direct use. An example is the Kagera region in Tanzania where the introduction of clean material of improved and better adapted cultivars from the ITC has contributed to agronomic improvements in farmers' fields, such as higher yield and reduction of losses to pests and diseases, including Mycosphaerella leaf spot and Fusarium wilt (Gallez et al. 2004). Other types of impacts refer to valuation of fundamental research carried out with materials from ITC (Table 1) and the body of knowledge on banana that has been generated, such as new technologies (Helliot et al.
2002; Van der Veken et al. 2007), improved understanding of the banana genome (D'Hont et al. 2012; Davey et al. 2013), diversity (Christelová et al. 2017; Sardos et al. 2016a, b; Janssens et al. 2016) and plant-pathogen relationship (Al-Idrus et al. 2017). In its role as a backup repository for field collections, the ITC is key in the restoration of diversity to the countries of origin or to broaden the conserved and available genetic diversity in national or regional field collections for research, direct adoption by farmers, and breeding or evaluation for breeding purposes (Garming et al. 2010). 
Table 1 The ten most cited and distributed accessions at the ITC

\begin{tabular}{|c|c|c|c|c|c|c|c|}
\hline \multicolumn{4}{|c|}{ Most cited in literature (2007-2018) } & \multicolumn{4}{|c|}{ Most distributed (2010-2019) } \\
\hline Rank & Doi & Accession name & \# publications & Rank & Doi & Accession name & \# shipments \\
\hline 1 & $\underline{10.18730 / 9 J M B D}$ & Calcutta 4 & 31 & 1 & $\underline{10.18730 / 9 J M B D}$ & Calcutta 4 & 72 \\
\hline 2 & $\underline{10.18730 / 9 M 56 P}$ & Tani & 16 & 2 & 10.18730/9MFBE & FHIA-23 & 45 \\
\hline 3 & $\underline{10.18730 / 9 J M 79}$ & Honduras & 15 & 3 & 10.18730/9J9D & Igitsiri (Intuntu) & 43 \\
\hline- & $\underline{10.18730 / 9 J M G J}$ & Borneo & 15 & 4 & 10.18730/9MRWQ & FHIA 25 & 43 \\
\hline 5 & $\underline{10.18730 / 9 J 9 P 5}$ & Mbwazirume & 14 & 5 & 10.18730/9MF9C & FHIA-17 & 40 \\
\hline- & $\underline{10.18730 / 9 K C D 6}$ & Khae & 14 & 6 & $10.18730 / 9 \mathrm{KC} 3 \sim$ & Pisang Mas & 39 \\
\hline 7 & $\underline{10.18730 / 9 J P C 4}$ & Long Tavoy & 13 & 7 & 10.18730/9JQQA & Pisang Jari Buaya & 38 \\
\hline- & $\underline{10.18730 / 9 \mathrm{M} 2 \mathrm{C} 6}$ & Agutay & 13 & 8 & $\underline{10.18730 / 9 M 56 P}$ & Tani & 37 \\
\hline- & 10.18730/9M2KD & Kunnan & 13 & 9 & 10.18730/9M5AT & Gros-Michel & 37 \\
\hline- & $\underline{10.18730 / 9 J M 13}$ & Safet Velchi & 13 & 10 & $\underline{10.18730 / 9 \mathrm{JgP} 5}$ & Mbwazirume & 36 \\
\hline
\end{tabular}

Distribution of germplasm has steadily increased with some peaks at certain years related to specific projects (e.g. the International Musa Testing Program, Musa genome sequencing and the establishment of the Musa Online Ordering System). The International Treaty has played an important role in the exchange of genetic resources through the establishment of a Standard Material Transfer Agreement. Nonetheless, on several occasions, the material distributed by ITC to National Agricultural Research Systems has been distributed to small scale farmers who commercialized it and benefited from this material with a potential impact towards the Sustainable Development Goals (SDGs 1 and 2).

\section{Cryopreservation for long term storage}

The most appropriate long-term ex-situ conservation method for vegetatively propagated crops such as banana is cryopreservation. Moreover, since edible bananas are seedless, conservation through seed is also not an option. Cryopreservation is the preservation of biological materials at ultralow temperatures, completely arresting all biological, chemical and physical processes. At these storage conditions-normally in liquid nitrogen $\left(-196^{\circ} \mathrm{C}\right)$ or its vapour phase (between -140 and $-180{ }^{\circ} \mathrm{C}$ ) - the materials can be stored for unlimited periods without any changes taking place. The main problem when exposing water-containing biological materials to such low temperatures is the occurrence of lethal ice crystals. Since the first report on cryopreservation of flax cell cultures in 1968 (Quatrano 1968), a variety of cryopreservation protocols have been developed for different kinds of materials; seeds, embryos, cell suspension and shoot tips of different species (Panis 2019).

The first report on cryopreservation of banana tissues dealt with embryogenic cell suspensions (Panis et al. 1990). Totipotent cells were stored in liquid nitrogen using the slow freezing process and successfully recovered, thus forming new embryogenic cell suspensions and normal plants (Cote et al. 2000). For the purpose of conservation of the widest possible diversity of bananas this method is, however, not preferred since the initiation of cell suspension is very time consuming and moreover, they are subject to somaclonal variation, or mutations caused by in vitro culture.

For the conservation of crop genetic resources, organized tissues like shoot-tips are commonly used. In case of bananas, cryopreservation of two meristematic tissue types has been reported; (i) highly proliferating meristem cultures containing 'cauliflower like" meristem clumps (Panis et al. 1996) and (ii) individual meristem cultures isolated from shoot tip cultures (Thinh et al. 1999; Panis et al. 2005). Although three published cryopreservation methods; simple freezing, droplet vitrification of sucrose precultured scalps and droplet vitrification of apical meristems each have their pros and cons, only the latter one is now used for the long-term storage of banana germplasm. The reasons for this are high and consistent post-cryopreservation regeneration rates between 50 and $90 \%$ and the fact that the method works for accessions belonging to all genomic groups of bananas.

A schematic overview of the protocol can be found in Fig. 2. In short, $1 \mathrm{~mm}$ sized meristems are excised under the microscope, exposed to the cryoprotective solutions, Loading Solution and Plant Vitrification Solution 2 , transferred to a small piece of aluminium foil and rapidly plunged in liquid nitrogen for storage. After storage they are rapidly rewarmed and recultured on a specific growth medium. The droplet vitrification protocol developed for banana meristems can now be considered as the first "generic" cryopreservation method for plant tissues, as it has now been successfully applied to different tissues (shoot cultures/embryos) and a wide variety of plant 


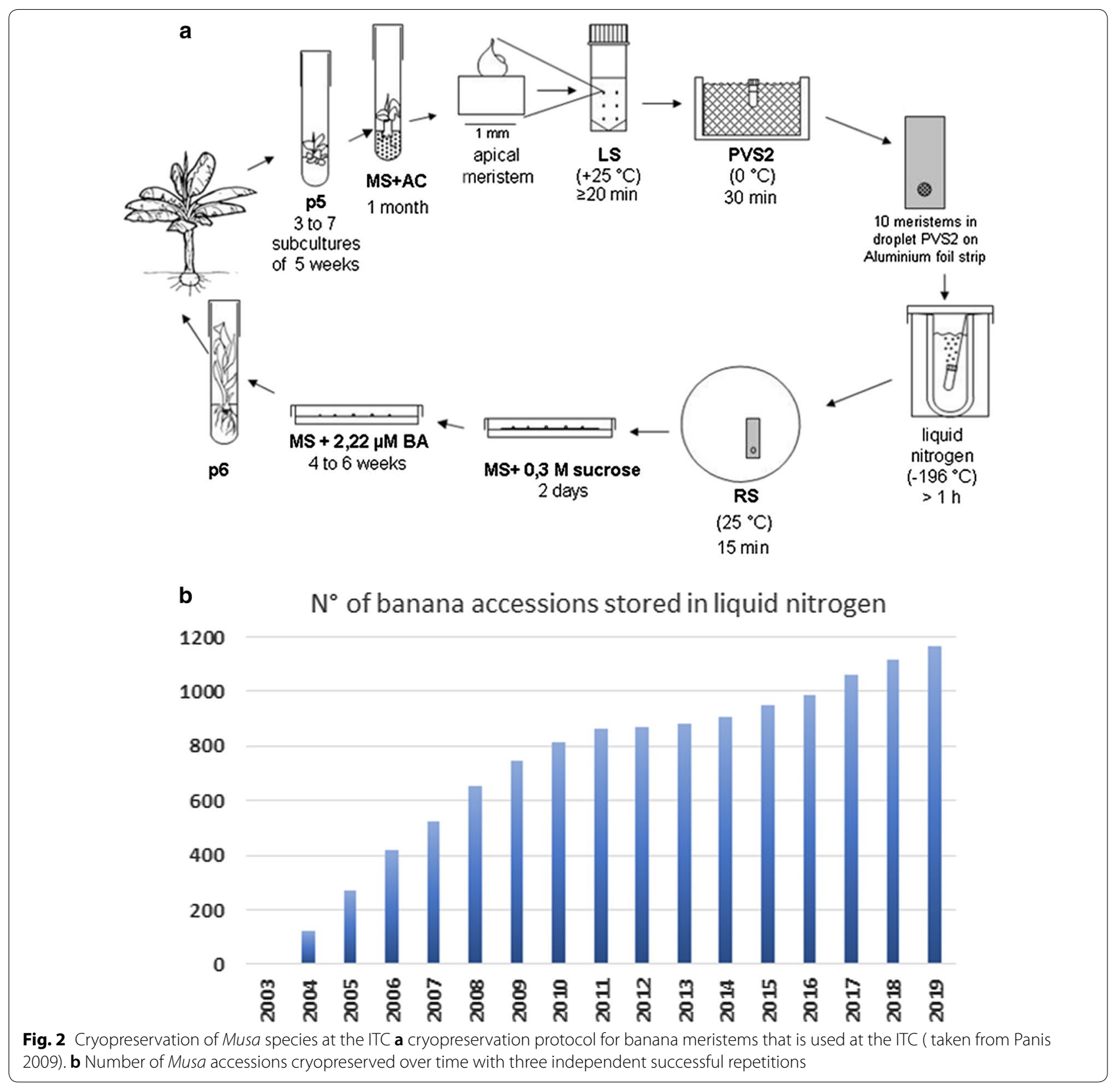

species from different climatic environments (Panis et al. 2011).

The routine cryopreservation of clean and field characterized banana accessions kept in the in vitro collection began in 2003. Since then each year the number of successfully cryopreserved accessions has increased, depending on the funding and the available materials. The ITC defines a banana accession as safely stored for the long-term provided three successful independent repetitions of at least 54 meristems are executed and for each successful repetition stored in the cryotank, there is a 95\% chance that at least one plant can be regenerated into a normal plant (Dussert et al. 2003). As such, one skilled lab technician can cryopreserve 40 to 50 banana accessions per year. As an additional security measure, one replicate set of all accessions has been transferred under frozen conditions to the Institut de Recherche pour le Development (IRD), Montpellier, France, using a dry shipper. This 'black-box' back-up is located $1000 \mathrm{~km}$ from the ITC, thus reducing the risk of germplasm loss due to political and/or environmental hazards. In 2017, a feasibility study for establishing a safety back-up 
cryopreservation facility was executed. This study, commissioned by Bioversity International, the International Potato Centre and the Global Diversity Crop Trust, describes the advantages of cryopreservation for conservation of clonal/recalcitrant seed crop collections and recommends that a major global effort is undertaken to facilitate its wide-scale implementation. Additionally, it highlights the necessity to establish a safety back-up facility to accommodate accessions arising from cryopreservation activities of all crops, like is done for banana (Acker et al. 2017).

\section{Seed bank}

\section{Importance of wild bananas}

Wild relatives of many crop species, including banana, are still largely underrepresented in genebanks. Nevertheless, they could be an inexhaustible resource of genes for disease resistance, drought tolerance and other desired characteristics that could be introduced in edible bananas through classical and modern breeding programs. Wild genetic resources, including those of banana, are in danger from abiotic and biotic pressures, as well as problems related to the increasing world population and subsequent habitat loss and/or fragmentation.

The genus Musa contains about 70 species and is grouped in two sections: Callimusa (incorporating Australimusa) and Musa (incorporating Rhodochlamys). The majority of edible cultivars are natural crosses derived from Musa acuminata subspecies, sometimes also comprising $M$. balbisiana genetic material. Both species belong the section Musa.

Field and in vitro collections can be used to conserve the diversity of wild bananas. However, to capture the full diversity of populations of wild banana species-and the potential genes for useful traits that they carryfield and in vitro conservation methods are insufficient.
Maintaining big populations this way would be too expensive and requires too much space. Seed storage in a global seed bank is therefore the preferred conservation option where viable. An agreement between Botanic Garden of Meise, Belgium and Bioversity International was recently signed to develop a wild banana seed conservation and regeneration facility and seeds will be collected when wild banana populations are found (Fig. 3) (see Gap Analyses and Collecting Mission section).

\section{Storing banana seeds}

Until recently no serious attempts were made to systematically collect and store wild banana genetic resources through seeds. Major obstacles were the unpredictable and mostly low seed germination rates, the unknown seed storage behaviour and the complete lack of knowledge on the genetic makeup of seeded Musa populations. The latter is needed in order to quantify how many seeds from how many banana plants and populations need to be collected in order to represent the entire genetic variability of a species. A final bottleneck is the restricted access to wild germplasm; indeed, wild bananas often grow in remote, inaccessible areas in Southeast Asia (Panis et al. in press).

Seed germination is determined by many parameters, the first one being the collecting. When collecting in the wild, timing of pollination and maturity of the bunch during harvest of the fruit, as well as the post-harvest treatment of the bunch all play a role (Simmonds 1952) and are all difficult to control. Also, the application of different seed extraction methods can lead to different results. Stotzky et al. (1962) discovered that Musa balbisiana seeds require alternating temperatures to germinate. This is linked to the habitat where wild bananas are growing, often in open canopy gaps where day/night fluctuations are the highest, and the soil is exposed to direct sunlight.

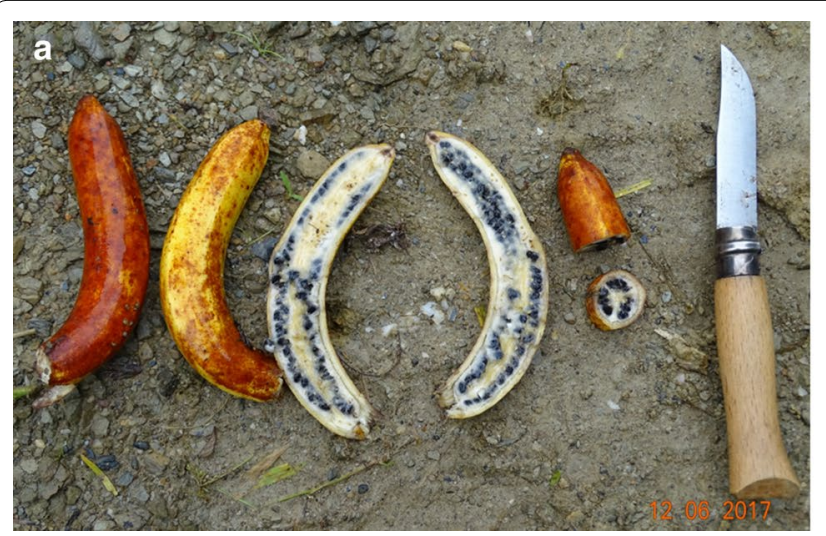

b

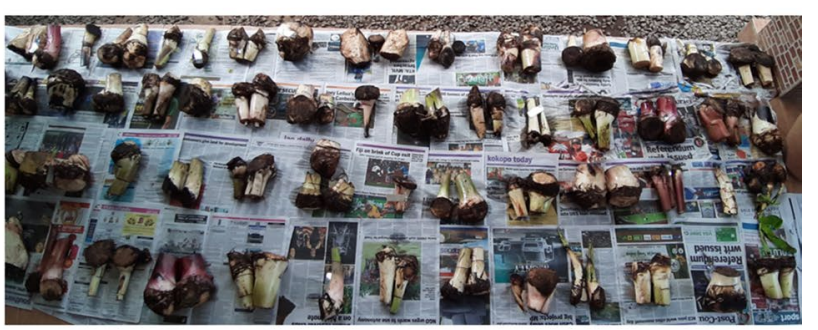

Fig. 3 a Populations of wild M. acuminata ssp. banksii were collected as seeds in 2017 in PNG. b Suckers of banana cultivars collected in the province of West New Britain (PNG) in 2019 and drying before shipment to PNG National Agricultural Research Institute 
Due to the low seed germination rates, storage experiments of wild banana seeds have not yet systematically been executed. This is the reason why sometimes embryo rescue is applied. For this, embryos are excised under sterile conditions and grown in vitro, thus avoiding he requirement for dormancy breakage and increasing the chance that a plant can be regenerated. According to the Seed Information Database from the Royal Botanic Gardens, Kew (2019), most of the members of the Musaceae family are considered to have an intermediate storage behavior. Other reports (Chin 1996; Simmonds 1952), however, confirm the results of recent experiments performed at the ITC; when seeds were sufficiently dried in a desiccator (to a moisture content below 10\%) and subsequently enclosed in airtight aluminum bags, they can be stored for at least 5 years at different storage temperatures.

Many of the population genetic and phylogeographic studies have been focusing on M. balbisiana and $M$. acuminata (Panis et al. in press). Restriction Fragment Length Polymorphism (RFLP) as well as Amplified Fragment Length Polymorphism (AFLP) and Single Sequence Repeat (SSR) markers have been used in several studies to investigate the genetic diversity and population structure of different Musa species (for an overview see Panis et al. in press). Recently, Bawin et al. 2019 analyzed seven batches of $M$. balbisiana originating from three natural populations, two feral populations and two ex situ field collections using SSR markers and recommended that additional collection of seeds should take place from natural populations, preferentially originating from the species' regions of origin, and from multiple individuals in each population.

\section{Characterization and monitoring genetic integrity Molecular characterization}

Since the rise of techniques allowing the molecular fingerprinting of plant materials, genotyping has been increasingly used to characterize crop germplasm and is now standard for genebank characterization (Spooner 2005; Kilian and Graner 2012). Based on molecular tools developed and used for research, a platform was set up to allow the standard genotyping of Musa genetic resources. This platform uses 19 SSR markers that were previously published and allow the efficient genotyping of any Musa accession. The combination of the different alleles obtained after the PCR amplification of the SSRs selected allow to discriminate identical genotypes and clonal groups of bananas, those sets of landraces or cultivars that are clonally derived from each other through accumulation of mutations or epigenetics mechanisms. It therefore constitutes a powerful tool to help refine taxonomy and check the identity of the germplasm (see section on field verification below). The platform was set up in partnership with the Institute of Experimental Botany (Christelová et al. 2011) and it operates under the name 'Musa Genotyping Centre'.

The Musa Genotyping Centre now routinely characterizes the accessions conserved in the ITC using a two-step methodology. Firstly, flow cytometry measurements are conducted to check the ploidy of the germplasm, that can be diploid, triploid and even tetraploid in banana. Secondly, SSR genotyping is performed using the set of 19 SSRs to determine the genomic constitution and/or the sub-group/sub-species level. Together, these methods increase the quality of the passport data of the collection, support the monitoring of the genetic integrity of the accessions conserved in the ITC and also help to describe and increase our understanding of the diversity of banana genetic resources globally (Christelová et al. 2017). The ITC germplasm is nearly fully characterized using these methods, but the Musa Genotyping Centre also offers different services to the Musa community that are of great help for germplasm conservation. For instance, flow cytometry and SSR fingerprints can be produced for any sample sent to the platform. In addition, published datasets are publicly available. Combined with the reference DNAs that are available upon request, they can be used to calibrate in house genotyping experiments (olomouc.ueb.cas.cz/en/content/ssrgenotyping). This was the case notably for the banana collection conserved at the USDA-ARS Tropical Agriculture Research Station in Puerto Rico, which successfully characterized its germplasm (Irish et al. 2014). The Musa Genotyping Centre also allowed the 'real-time' characterization of the germplasm collected during collecting missions in Indonesia in 2012 and 2013 (Christelová et al. 2017) and recently in the Autonomous Region of Bougainville (Papua New Guinea) (Sardos et al. 2018). The platform therefore has become a powerful and affordable way to characterize banana germplasm globally and is an essential tool for and efficient conservation and use of banana germplasm.

In addition to the SSR genotyping undertaken with the Musa Genotyping Centre, part of the germplasm conserved in the ITC was also characterized in independent studies. Phylogenetic markers such as ribosomal ITS and chloroplast sequences are available for a number of accessions (Boonruangrod et al. 2009; Li et al. 2010; Č́źžková et al. 2015; Janssens et al. 2016), DArT markers were applied to nearly 600 accessions (Sardos et al. 2016a) and Genotyping-By-Sequencing was performed on a sub-set of 105 diploid accessions (M. acuminata and AA) with the aim to perform genome-wide association studies (GWAS) (Sardos et al. 
2016b). The datasets from these studies are available and displayed in the on-line Musa Germplasm Information System (Ruas et al. 2017) in the 'genotyping studies' section (https://www.crop-diversity.org/mgis/ genotyping-study-list).

\section{Field verification}

The monitoring and maintenance of genetic integrity of the ITC in vitro collection is essential to ensure that only healthy and true-to-type accessions are conserved and distributed to the public. This ongoing activity, called field verification, allows to identify those accessions that underwent somatic mutations due to tissue culture or that were accidently mixed-up. It also allows to check the taxonomy of the germplasm. It requires the expertise and efforts of many players (Chase et al. 2014). The field verification cycle starts with accessions that have been conserved in vitro at the ITC for more than ten years (Fig. 4). They are sent to USDA-ARS TARS in Puerto Rico, where they are grown and morphologically characterized in their field collection using the minimum standard banana descriptors (Taxonomy Advisory Group, 2016) and photographs (Taxonomy Advisory Group, 2010). Concurrently, the accessions undergo ploidy determination and molecular characterization (see Molecular Characterization section). Next, both sets of data are compiled for

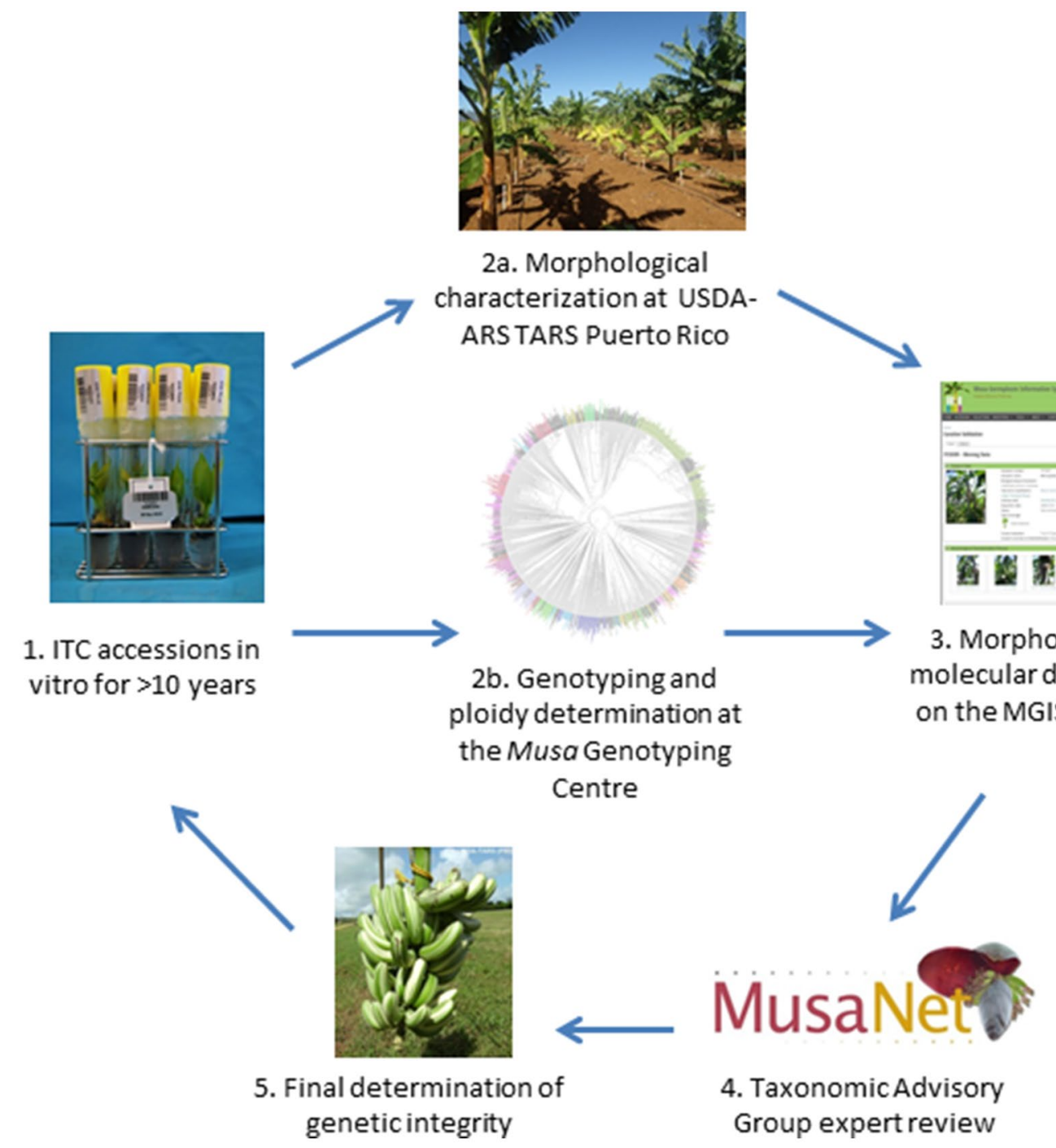

Fig. 4 The workflow of the field verification activity, starting with ten year-old accessions at the ITC (1), that are sent to the field verification site in Puerto Rico (at USDA) and the Musa Genotyping Centre for characterization (2a/2b), after which the data are compiled in the Musa Germplasm Information System (3), sent to the Taxonomy Advisory Group (4) who take a final decision on genetic integrity (5) 
review by the ten experts of the Taxonomic Advisory Group of MusaNet (https://www.musanet.org), via a customized dashboard on the Musa Germplasm Information System (Ruas et al. 2017).

For a decision on integrity to be taken, at least two experts must be in agreement on an accession's status as either: true-to-type, true-to-subgroup, misclassified, mislabelled or off-type. True-to-subgroup and true-to-type accessions are thus both maintained in the ITC collection and available for distribution. Misclassified accessions are subject to further evaluation for correct classification, while mislabelled and off-type accessions are in most cases removed from the in vitro collection and thus not available for distribution. If the conclusion is not clear (e.g. morphological and molecular results not in agreement), many of the mislabelled and off-type accessions are re-evaluated. When accessions are removed from distribution, efforts to replace them are made by contacting the donor institutions or sourcing the same accessions elsewhere. No accessions are removed from long-term storage, i.e. cryopreservation.

As of June 2020, out of the 571 ITC accessions that have undergone field verification, $80 \%$ of them are trueto-subgroup or true-to-type, while the remaining are mislabelled (10\%), misclassified (6\%) and off-type (4\%).

In addition to ensuring the collection's integrity, a large body of useful information is generated by the field verification activity and is accessible to the public via the Musa Germplasm Information System, including characterization data and photographs. This information adds significant value to the ITC collection and is a clear asset to the Musa community.

\section{Phenotypic evaluation of the collection for key agronomic traits}

Genetic diversity has the potential to alleviate yield gaps and mitigate the risk of annual yield loss in many crops (Foley et al. 2011). The genetic characterization and evaluation of suitability of genebank accessions for targeted agro-ecological regions and markets has been proven to contribute to increased food, feed, fiber and fuel demands (McCouch et al. 2012). In case of banana, a set of "climate smart" banana accessions can help to mitigate the risks of an erratic climate (Machovina and Feeley 2013; Rippke et al. 2016) and to close the yield gap in the African Great Lakes region and beyond (Kamira et al. 2016; Ocimati et al. 2014; Turner et al. 2016). Their diversity is not only vital to optimize yield and anticipate climate change, it is also decisive to identify useful alleles and to introduce genetic diversity into the narrow genetic basis of the edible bananas (pre-breeding aspect). However, as long as genebanks are not fully characterized, phenotyped and accessible on a web platform such as the Musa Germplasm Information System (Ruas et al. 2017) or Genesys (https://hww.genesys-pgr.org), it is difficult for stakeholders to realize the potential of the stored accessions and it is challenging for the curators to comprehend what is "missing" in their germplasm collections.

Unique key traits need to be defined with stakeholder input and prioritized to phenotype and genetically characterized. Past efforts to improve and stabilize banana production systems focused on soil-borne problems (Fusarium wilt, nematodes and weevils), foliar diseases (black leaf streak, banana Xanthomonas wilt, banana bunchy top virus), abiotic factors (declining soil fertility and drought) and socioeconomic factors (marketability, acceptability, sensory characteristics). The most effective practice to screen pathogen and pest resistance of banana is by planting disease-resistant varieties in infested fields. Screening can also be carried out under greenhouse conditions. Both practices have advantages and disadvantages, which are largely influenced by stakeholder objectives, the number of genotypes screened, the time and costs involved, and the available facilities. Field phenotyping provides information on the host reaction under real-life conditions. However, it requires large experimental plots, is time-consuming (more than three years) and is highly demanding in terms of manpower. Initial disease/pest pressure and soil characteristics may also vary considerably across the experimental site, and the development of symptoms may be affected by climatic conditions. The use of rapid and reliable methods for early detection of resistant genotypes under greenhouse conditions could swiftly identify promising genotypes and generate knowledge about the genetic and molecular basis of resistance. However, greenhouse screening is often performed under artificial conditions, which include high inoculum levels, young plants, and controlled soil and environmental conditions that may not reflect field conditions. Ideally, early screening in the greenhouses should be used to identify genotypes that will then be evaluated in the field.

To evaluate how "climate smart" banana genotypes are in some strategic agro-eco zones, key agronomic traits for banana need to be evaluated in function of local climatic conditions. An improved understanding of crucial developmental stages and which climate variables have the biggest impact in major banana growing regions is very informative for national agricultural research centers. This knowledge allows them to know what genotypes to distribute and will help to develop specific breeding goals for different regions of the world. Special attention needs to be given to tolerance traits during the critical stages in the ontogeny (Gibbs and Turner 2018). The life cycle of bananas can be divided into three phases: the 
vegetative, floral and fruit phase. The interaction between seasonal changes in temperature, photoperiod and soil water balance influences the timing of the transition from vegetative to floral phase, contributing to seasonal variation in flowering and bunch harvest (Gibbs and Turner 2018). The rate of development of a banana plant is influenced by temperature and since in a certain environment temperature is more stable, the short-term growth is predicted to be more a function of water supply (Turner 1990). However, in contrast to water, the temperature cannot be controlled by farm management. The importance of temperature is illustrated in the use of thermal time rather than absolute time to indicate the duration between planting and harvest.

Key agronomic traits are: bunch weight, plant annual yield, ratoon crop cycle, plant height, number of hands in bunch, number of fingers in hand, finger weight and number of suckers (see https://www.cropontology.org/ ontology/CO_325/Banana) (Shrestha et al. 2012). Key climatic variables that need to be measured during the three important phenological stages of banana can be found in Kehel et al. 2016.

In an agricultural approach, an abiotic "stress" is a disadvantageous influence coming from the environment, threatening yield. Hence, growers focus on reducing abiotic stress to safeguard their production and profit. Plant growth is determined by the interaction of the genotype with the environment, while crop growth is determined by the interaction of the Genotype with the Environment and the farm Management (GxExM). Absolute classifications of genotypes towards tolerance are therefore not possible. The terms "susceptible" and "tolerant" are relative terms which depend on the given set of genotypes evaluated under a given set of environmental conditions. Ideally, all genotypes need to be screened in the field in the area of interest for at least two crop cycles. However, screening numerous banana genotypes from start to harvest would be extremely labor, time and cost intensive. Therefore, as it is the case for biotic stress screening, a workflow is required where the existing biodiversity is first screened through an early screening process in a controlled environment, especially if a link is to be made to molecular analysis (Fig. 5). This concept is already known in the breeding community as rapid phenotyping (Ghosh et al. 2018). By simulating different climates in a sophisticated controlled lab environment (the bananatainer) (Fig. 5), we apply this speed concept on the ITC collection. Currently, a strategic subset of the ITC collection is being screened for potential varieties that have good growth performance for the different East African agro-eco zones. In a next phase, the promising genotypes will be validated in the greenhouse and in a third phase a selected set of genotypes will be tested in strategic agroeco zones for agronomical performance and consumer acceptance.

\section{Genebank genomics}

Next Generation Sequencing (NGS) techniques have drastically modified our ability to screen diverse germplasm at large scale in genebanks (Kilian and Graner 2012; McCouch et al. 2012). The release of a quality reference genome sequence for the main ancestor of cultivated bananas, M. acuminata, the A genome (D'Hont et al. 2012; Martin et al. 2016), represented by the 'double haploid Pahang' and a draft genome for the second main ancestor, $M$. balbisiana, the B genome represented

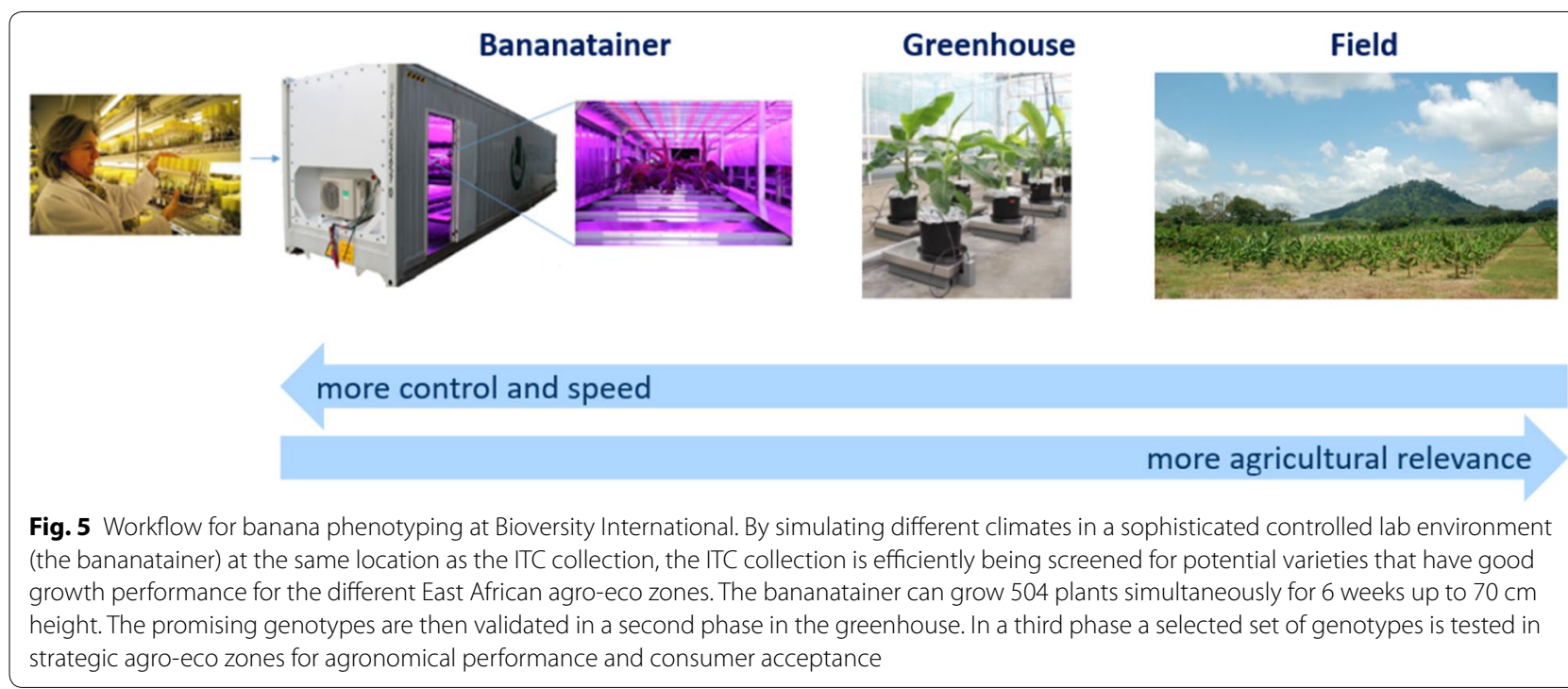


by 'Pisang Klutuk Wulung' (Davey et al. 2013), both held at the ITC, paved the way to the promising field of genebanks genomics. Since then, about one-third of the ITC collection has been sequenced by High Throughput Genotyping (Elshire et al. 2011; Davey et al. 2010). These studies benefit genebank users by boosting our understanding of the banana (Musa spp.) genetic diversity and ultimately by leading to an optimized management of the genebank collections.

\section{Deciphering the evolutionary history of the crop}

Genomic data have greatly helped clarify the evolutionary history of wild species and cultivated groups conserved at the ITC. In wild bananas, studies of whole genomes allowed to detect phenomena such as whole genome duplications and translocations (D'Hont et al. 2012; Martin et al. 2016; Dupouy et al. 2019) as well as evidence of rapid radiation of these $M$. acuminata subspecies (Rouard et al. 2019). In cultivated bananas, the chromosome structures of allopolyploid hybrids were explored allowing to clarify the path that led to their creation (Baurens et al. 2019; Cenci et al. 2019, 2020). Current efforts focus on resolving the mosaic structure of cultivated banana by looking at the ancestral contribution of the different $M$. acuminata subspecies along chromosomes (Martin et al. 2020). This information will be of particular importance for breeders requesting material. Additional insights should also come from recently generated high-quality reference sequences of $M$. balbisiana (B genome) (Wang et al. 2019) and M. schizocarpa (S genome) (Belser et al. 2018). New genomes like M. textilis ( $\mathrm{T}$ genome) will be useful resources to extend analyses to the section Callimusa, formerly Australimusa, that comprises Fe'i bananas cultivated in the Pacific.

\section{Gene-trait association}

Genome sequence information is a powerful tool to help identify allele variation linked to agronomic characters desirable for breeding (Mascher et al. 2019). In banana, genome-wide association studies (GWAS) have led to the identification of useful diversity and molecular markers for sterility and parthenocarpy (Sardos et al. 2016a, b). This study has proved GWAS to be applicable to banana despite the vegetatively propagated nature of the plant. It also provided to users a panel of diploid accessions and markers to investigate additional traits, even though information on a range of important farmer-preferred traits is still lacking to enable the use of this approach. Meanwhile, other omics datasets have been produced, notably on differential gene expression analyses and proteomics for a number of priority traits. With respect to accessions available in the ITC collection, this is the case for drought (Zorrilla-Fontanesi et al. 2016; Kissel et al. 2016; Wesemael et al. 2018) and pests and diseases (Passos et al. 2013; Timm et al. 2016; Zhang et al. 2019). However, given their elevated costs, techniques such as RNAseq for gene expression have only been applied to a very limited number of samples. Moreover, although many gene expression studies have been conducted, the plant materials used do not always originate from a genebank, which hampers further use of the same material in other studies. Subsequent analyses could be facilitated by selecting priority material coming from genebanks or by transferring promising material to genebanks as a later step. Finally, metabolomics studies were initiated on banana as proofs of concept and enabled the identification of specific metabolite profiles using a diversity panel of 38 genebank accessions (Drapal et al. 2019), now being extended to breeding material (Drapal et al. 2020). The ideal scenario is that the molecular analysis is integrated and combined with phenotyping (Zivy et al. 2015; Jamil et al. 2020).

\section{Support for management of the collection}

Assessment of banana genetic diversity has long been done using morphological descriptors and was later complemented by molecular markers. NGS data demonstrated their power to refine the current taxonomic classification that was established using morphological descriptors. It notably facilitates the categorization of material to the correct groups or subgroups using molecular karyotypes (Baurens et al. 2019; Cenci et al. 2020). Although diploid AAs and auto-triploids remain more challenging as they involve genomic sections inherited from the different $M$. acuminata genepools, this was recently initiated with a small number of accessions from the ITC and other banana collections (Martin et al. 2020). The results obtained showed that this type of data may also help resolve taxonomic conflicts in these AA and AAA cultivars.

A big issue for genebanks conserving their material in vitro, such as the ITC, is the occurrence of somatic mutations that alter the genetic integrity of the germplasm. Genomic approaches to germplasm showed that large deletions or large duplications (i.e. aneuploidy) might be associated with somatic mutations. Such mutations are traditionally detected through the field verification process that is long and complex (as described in field verification section). Even though the links between the off-type status of the accessions and these aberrant chromosome rearrangements need to be further investigated, NGS technologies offer promising prospects for their use in the routine management of 
the ITC. NGS could be used to perform complementary screening of the accessions and a first protocol has been recently developed to detect large chromosome rearrangements (Breton et al. submitted) which could aid the early detection of off-type accessions.

\section{The banana genebank information systems}

The ITC relies on two distinct and complementary information systems, one dedicated to the internal management of the genebank operations, and the other disseminating information about the diversity of the ITC collection and other ex situ collections worldwide.

\section{Musa Genebank Management System (MGBMS)}

Operating a genebank and curating accessions in collections is highly complex work. Indeed, each accession in the genebank is split into several types of physical material such as accessions preserved in vitro that need regular subculturing and quality assurance checks, accessions processed and stored in the cryobank, plants grown out in the greenhouse (for rejuvenation or observation purposes), leaf tissue samples harvested and maintained in the lyophilized tissue bank, in vitro samples that are subjected to health tests, characterization and then distributed in response to users requests. Each of these procedures generate a large body of data and information that is essential for the proper documenting and functioning of the genebank. Hence, it is of critical importance that management data and comprehensive information is recorded in an appropriate database system to ensure the integrity and security of the data stored and to support operational efficiency of the genebank (e.g. identify critical bottlenecks and needs).

At the ITC, a fully customized database system was developed in 2001 to manage the genebank activities and the associated data on a day-to-day basis. The system covers the genebank processes related to the acquisition, conservation, health testing, characterization, and distribution of accessions at the ITC. It includes barcoding and recording of data via mobile devices to reduce mistakes in the identity of the materials in the genebank. The current version of the system is fully workflow-oriented and highly integrated in the everyday activities of the genebank staff. ITC staff curate accession-level information, including passport information (unique accession code, name, source and taxonomy) using the $\mathrm{FAO} /$ Bioversity International multi-crop passport descriptors (Alercia et al. 2015) and, since recently, the Digital Object Identifier (DOI) unique identifiers assigned via the Global Information System (GLIS) of the International Treaty. These data comprise the information of all physical material of an accession present in the genebank. The application installed on mobile devices and connected to barcode readers and printers is used by the genebank operators for capturing, viewing and editing data associated with the various physical materials of the accessions in the genebank.

The system also records orders for germplasm that are placed via the online ordering tool. Documents related to the distribution as well as the acquisition of germplasm (i.e. scanned SMTAs, phytosanitary, packing document and photos) are stored in the system; the same for germplasm transfers from the genebank to users that need to be reported in accordance with the International Treaty.

\section{Musa Germplasm Information System (MGIS)}

The main community portal to retrieve information on banana is called the Musa Germplasm Information System (MGIS) (Ruas et al. 2017), based on the open source Drupal content management system and Tripal, a toolkit that facilitates construction of online genomic, genetic, breeding or other biological databases (Ficklin et al. 2011; Sanderson et al. 2013).

\section{Information on passport and morphological diversity}

MGIS contains key information on Musa germplasm diversity, including multi-crop passport data, botanical classification, morpho-taxonomic descriptors, studies, photographs and geographic information on 6619 accessions managed in 30 collections around the world, making it the most extensive source of information on banana genetic resources (https://www.crop-diversity. org/mgis/organisations). The data are provided under a Data Sharing Agreement to ensure better recognition of work done by partners. The quality of the passport data provided is scored by using the Passport Data Completeness Index developed by van Hintum et al. 2011b, 2011a. A specific version of the index to Musa has been developed to consider additional information collected on passport data such as the history of prior movement of the germplasm across collections (https://www.cropdiversity.org/mgis/accession/01BEL084609). To lower the level of error when recording descriptor values, as well as ensuring homogeneity in data collected, we developed a mobile application (https:/www.crop-diversity.org/mgis/ content/musatab), which not only guides the data capture, but also facilitates photo capture of specific traits. All this information, delivered in a comprehensive framework, can help users identify material of interest. Once identified, the material from the ITC can be requested on the website which automates PDF form-filling through a three-step process to generate the SMTA. 


\section{Information on allele and trait diversity}

Phenotyping and genetic diversity studies are included in dedicated sections that provide an easy way to explore the accessions. For studies using genetic markers such as SNPs, we upscaled the system with an optimized tool (Sempéré et al. 2019) which provides an easy and intuitive way to explore large amounts of SNP data produced on genebank accessions (www.crop-diversity.org/mgis/ gigwa). It offers a scalable solution to search for genotype patterns, functional annotations, or more complex filtering as well as data export in multiple format types. Datasets from several published studies have also been made available (Sardos et al. 2016a, b; Cenci et al. 2020).

\section{Curation to monitor the use of accessions}

The use of ITC accessions is documented based on a literature review. Each accession reported in a publication with an ITC accession number is added to MGIS to inform users about what type of data, information and knowledge exists about that accession. It also allows users to generate statistics about the most popular accessions in the ITC (Rouard et al. 2018) (Table 1). As an example, the most cited and distributed accession is a M. acuminata subspecies burmaniccoides called 'Calcutta 4'. 'Calcutta $4^{\prime}$ has been used extensively in breeding because of its resistance to black leaf streak. It is also resistant to several races of Fusarium wilt and partially resistant to Radopholus similis and other nematodes. It is followed by 'Tani', a representative accession of the M. balbisiana genome. The trend in the most cited accessions are for wild and diploid accessions (AB), with the exception of 'Mbwazirume' (AAA group), while wild accessions represent only $17 \%$ of the distributed material.

\section{Interoperability with other systems}

Passport data information linked to ITC is transferred to the global portal Genesys (https://www.genesys-pgr.org/ wiews/BEL084) managed by the Global Diversity Crop Trust and synchronized with the Global Information System (https://ssl.fao.org/glis/entity/search?SearchForm[h oldwiews] =BEL084), which was established by the International Treaty to facilitate the exchange of information. Since 2018, the ITC collection uses Digital Object Identifiers promoted by the International Treaty to reinforce tracking of the material. A community portal called the Banana Genome Hub (Droc et al. 2013) has been developed to provide easy access to all types of genomics data and enable genome exploration using genome browsers that are connected to marker datasets maintained in MGIS. This ensures that genetic material is properly described and accessible for any subsequent experiment. Genetic information can also be tracked back to the original material. Monitoring the use of accessions is also fostered by linking with breeding program datasets. For example, using a common application programmatic interface called the Breeding API (Selby et al. 2019), the Musa Germplasm Information System and MusaBase (https://musabase.org/) are connected and can exchange useful information for their respective target audience. The advantage is an additional source of information from breeding programmes about genebank material for which evaluation or phenotyping was carried out but not readily accessible from MGIS.

\section{Gap analyses and collecting missions}

The MGIS provides access to important information on banana germplasm conserved in international and national ex-situ collections and is of great help in assessing the extent of diversity safeguarded globally. This diversity has been collected in farmers' fields or in the wild.

Banana has a long record of collecting expeditions, but not all the materials prospected are still available in genebanks. For example, the expeditions led by N. Simmonds in East Africa in 1948 and in Asia and the Pacific in 1954 and 1955 for the Imperial College of Tropical Agriculture (Simmonds 1956) led to a significant increase of our knowledge on bananas, but very few samples collected at the time were maintained. On the contrary, the results of the extremely fruitful collecting missions organized by the United Fruit Company in 1959-1961, co-led by P. H. Allen and and J. J. Ochse (Rosales et al. 1999), are still partly available for the community, since the entire collection entered the public domain in 1984 when the Fundación Hondureña de Investigación Agrícola (FHIA) started to manage it. A back-up of this germplasm was initiated, and more than 120 accessions are still conserved in the ITC. As FHIA's collection started to decline in the 2000's, this back-up initiative saved some of the invaluable banana germplasm gathered by Allen and his colleague. This last example shows how important it is to organize collecting activities in a synchronous way with both national partners and the ITC. The first successful example of such harmonized organization was in the late 1980s, when a set of collecting expeditions was organized to Papua New Guinea (PNG) jointly with Australian institutions, the ITC and the PNG National Agricultural Research Institute. These missions ended with more than 250 accessions collected, of which most are still conserved in the ITC more than 30 years later (Sharrock 1988, 1989; Sharrock et al. 1988, 1989; Arnaud and Horry 1997).

Equally, not only the organization of collecting missions have evolved, but their scope has too. Until recently, collecting missions were mostly driven by the need to find new parents to breed commercial bananas 
(e.g. Simmonds 1956; Rosales et al. 1999). However, in the 1980s, evidence for the erosion of wild habitats and for the progressive loss of traditional agro-systems in favor of less diversified cropping systems induced shifts in mindsets. Collecting missions therefore not only targeted material for breeding but also aimed at safeguarding the widest amount of diversity possible before it goes extinct (e.g. De Langhe et al. 2001; Sharrock 1988). In this perspective, gap analyses were carried out to identify priority areas and taxa for conservation. A global analysis of the conservation status of the crop wild relatives of 81 crops identified wild bananas as priority taxa for conservation due to their poor representations in genebanks (Castañeda-Álvarez et al. 2016). In parallel, a consultation of experts held in a MusaNet workshop in Bogor, Indonesia, realized the taxonomic uncertainty of wild bananas may hamper the correct assessment of the wild taxa to focus on and rather identified regions for which little germplasm was available in ex situ facilities. This exercise, combining cultivated and wild bananas, identified Indonesia, South Philippines, Myanmar, Northeast India and near Oceania, including the archipelago of the Solomon Islands, as priority areas (MusaNet 2016).

Following this consultancy process, two collecting missions were organized jointly with the Indonesian Center for Horticultural Research and Development to North Sulawesi in 2012 and in Ambon and Seram in 2013. In 2016, when the opportunity arose to organize a new collecting expedition, the Autonomous Region of Bougainville (in PNG) located at the northern tip of the Solomon archipelago was selected (Sardos et al. 2017). Finally, a recent and fine-scale analysis considering both the genetic background and the geographical origins of the accessions conserved in the ITC was performed (Giovannini et al. 2019). Among others, this last approach identified gaps in germplasm originating in the Pacific in general, especially for Fe'i bananas, and in the western side of the island of New Britain for all banana germplasm in PNG. Therefore, three collecting missions were organized in 2019 to Cook Islands, Samoa and the PNG province of West New Britain (Sardos et al. 2019a, b, 2019a). All the collecting missions were organized jointly with local institutions and the germplasm collected is in the process to be backed-up in the ITC. The results of these recent expeditions are displayed in Table 2.

An additional important gap identified for banana crop wild relatives was the conservation of wild bananas as populations (see Seed bank section). Most of the banana ex-situ conservation facilities indeed focus on the vegetative conservation of single individuals, inducing the collection of single suckers of wild banana plants rather than populations. The experts therefore encouraged the collection of populations under the form of seeds (MusaNet 2012). It was done during the two collecting missions to Indonesia in 2012 and 2013, but no specific seed conservation facilities existed at the time. In addition, two dedicated expeditions were organized to PNG in 2017 and 2019, respectively (Sardos et al. 2017; https://www.cwrdi versity.org/wild-about-bananas/).

Finally, experts specified during the consultancy process that, due to the poor representation of wild taxa in genebanks, the collection of banana's crop wild relatives should not be focused on traits but on diversity and that phenotyping and evaluation for specific traits should be carried out after collection (MusaNet 2012). However, as it was demonstrated that climate change will exacerbate food insecurity in vulnerable areas (Wheeler and Von Braun 2013), collecting expeditions for both cultivated banana and their wild relatives with specific focus on traits such as drought tolerance or resistance to climate sensitive diseases could take place in the future.

Table 2 Numbers of accessions collected during the expeditions organized since the establishment of MusaNet in 2011

\begin{tabular}{|c|c|c|c|c|c|c|}
\hline & \multirow{2}{*}{\multicolumn{2}{|c|}{ Cultivated (suckers) }} & \multicolumn{4}{|l|}{ Wild } \\
\hline & & & \multicolumn{2}{|c|}{ Suckers } & \multicolumn{2}{|c|}{ Seed lots } \\
\hline & Musa & Call. (Fe'i) & Musa & Call & Musa & Call \\
\hline North Sulawesi and North Maluku (Indonesia 2012) & 18 & - & 3 & 3 & 5 & 3 \\
\hline Central Maluku and Sunda Islands (Indonesia 2013) & 6 & 2 & 8 & - & 7 & - \\
\hline Autonomous Region of Bougainville (PNG 2016) & 50 & 7 & 1 & 3 & - & 11 \\
\hline Madang and Morobe provinces (PNG 2017) & - & - & - & - & 15 & 6 \\
\hline Rarotonga and Aitutaki Islands (Cook Islands 2019) & 11 & 7 & - & - & - & - \\
\hline Madang, Morobe and Sandaun Provinces (PNG 2019) & - & - & - & - & 21 & 11 \\
\hline Upolu Island (Samoa 2019) & 10 & 4 & 2 & - & - & - \\
\hline West New Britain Province (PNG 2019) & 66 & 4 & 1 & 1 & - & 3 \\
\hline
\end{tabular}

'Musa' and 'Call.' stand for the botanical sections Musa and Callimusa respectively. 'Seed lots' refers to seeds collected from a single mother plant 
More than ever, coordination and synchronization with national partners will be necessary to achieve this task.

\section{Networking with MusaNet}

MusaNet (https://www.musanet.org) is the Global Network for Musa Genetic Resources, founded in 2011 by Bioversity International, and comprising over 100 members from various banana research institutes and organizations that support Musa research. MusaNet aims to optimize the conservation and use of Musa genetic resources by coordinating and strengthening the conservation and related research efforts of a worldwide network of public and private sector stakeholders.

MusaNet has as its mandate to further develop and implement the Global Musa Strategy (see Introduction) and to disseminate the fruits of its research by providing technical guidelines and building capacity in the banana-producing regions, for example at regional workshops on characterization and documentation of field collections.

The network is divided into five thematic groups where members build global and cross-thematic collaboration. The Conservation, Diversity, Evaluation, Genomics and Information Thematic Groups are each led by an elected Chair and Co-chair, who represent the group at the monthly Expert Committee meetings. A selection of recent activities from each thematic group are highlighted below in Table 3 .

The three regional banana networks (BAPNET, MusAfrica and MusaLAC) are federated through MusaNet to ensure that the links with national partners remain strong and to keep abreast of the needs of the regions, such as pest and disease prevention and mitigation. The networks are also represented in the Expert Committee, along with the coordinator of ProMusa (https://www.promusa.org), the banana information sharing platform, also coordinated by Bioversity International.
The ITC plays a central role in MusaNet, as it exchanges germplasm and information with many of the over 60 Musa collections worldwide and is involved in activities of all five thematic groups. The genebank also has forged a strong relationship with many regional and national collections by providing a back up to their collections and collaborating on collection missions, research and capacity building.

\section{Conclusion}

Over its 35 years as the global banana genebank, the ITC has continually grown both in size and in relevance to the Musa research community, having integrated key research activities and novel methods and tools to conserve, help understand and promote the use of its germplasm. It's primary objective as a CGIAR genebank, under the auspices of FAO and regulated by the International Treaty, is to conserve and make publicly available its collection to the highest standards possible. Beyond that role, significant value has been added to the collection by the related activities described in this chapter, including cryopreservation, seed banking, molecular characterization, phenotyping, genomics, bioinformatics and comprehensive accession-level documentation.

Many of the challenges laid out in the introduction of this chapter on conservation, use and access to material have or are currently being addressed at the ITC. Other challenges will be met by further activities and future perspectives to increase the value and accessibility of the genebank for the public, researchers and breeders alike.

Regarding the distribution of germplasm, the ITC will in the next few years increase the immediate availability of its accessions to $90 \%$ of the collection thanks to the strategic release and cleaning of accessions containing endogenous banana streak virus sequences. The Germplasm Health Unit is also developing High Throughput Sequencing technologies as a universal diagnostic test for accurate and sensitive detection of plant viruses.

\section{Table 3 Recent activities within the five MusaNet thematic groups, many of which are discussed in this chapter}

\begin{tabular}{|c|c|}
\hline Thematic Group & Activity \\
\hline Conservation & $\begin{array}{l}\text { Technical Guidelines for the Safe Movement of Musa Germplasm (Thomas et al. 2015); Virus Ring Test training for National Agricul- } \\
\text { tural Research Systems to detect banana viruses; development of a strategy to distribute accessions with endogenous Banana } \\
\text { Streak Virus }\end{array}$ \\
\hline Diversity & $\begin{array}{l}\text { Collecting missions to Papua New Guinea, Indonesia, West New Britain, Bougainville, Cook Islands and Samoa (Sardos et al. } 2017 \text {, } \\
\text { 2018, 2019a, b); the Taxonomic Reference Collection; the development of minimum descriptor lists for Musa, Plantains and East } \\
\text { African Highland Bananas; Regional workshops on field characterization }\end{array}$ \\
\hline Evaluation & Evaluation protocols for resistance of drought, black streak virus and Fusarium Wilt; IMTP evaluation trials \\
\hline Genomics & $\begin{array}{l}\text { Annual workshop at the Plant Animal Genome conference; genotyping including resequencing of ITC accessions; sequencing of } \\
\text { reference genomes for Musa acuminata subspecies }\end{array}$ \\
\hline Information & $\begin{array}{l}\text { Development of mobile applications for morphological description and for taxonomic identification; iNaturalist for crowd-sourced } \\
\text { with the banana natural biodiversity mapping project; Updates data and features for information systems }\end{array}$ \\
\hline
\end{tabular}


Concerning long-term conservation, the proposed international safety back-up cryopreservation facility will safeguard clonal/recalcitrant seed crops such as banana.

Collecting wild species and cultivars in situ and on farm remains important to fill critical gaps in the ITC collection, and to establish strong collaboration and access benefit sharing with national partners. Adding material to genebank collections has become more difficult, not only because collecting missions need to be negotiated with national and local authorities, but also because acquiring material from other collections is only possible if the origin of the material is properly documented and is done in compliance with regulations (Brink and van Hintum 2020). Although considerable progress has been made, more work related to germination, preservation, population genetics and collection of wild bananas is still needed to establish an active wild banana genebank.

Towards the better use of the collection, molecular and morphological characterization data continues to increase in quantity and quality. Genotyping studies will further elucidate the taxonomy and link genes to phenotypic traits, while the evaluation of biotic and abiotic stresses using improved protocols and technologies, such as the 'bananatainer', will reveal important 'climate smart' traits inherent in Musa diversity.

Research on genetics and epigenetics will allow a better understanding of somatic variation in banana and the development of a system for early detection and control. Genomic and bioinformatic analyses will play an increasingly important role in understanding the genetic variation of banana diversity. Given the affordable cost of Next Generation Sequencing approaches, an increase of genomic studies with larger sampling is expected, ultimately leading to a full coverage with genomic data of the international genebank to maximize its use (Halewood et al. 2017). Additional insights should also come from new high-quality reference sequences from the B and S genomes (Belser et al. 2018; Wang et al. 2019).

The Musa Germplasm Information System database is continuously expanding its comprehensive dataset on banana accessions held collections across the globe, and integrating phenotyping studies is a current priority, despite the challenging level of details and volume of information. Users are interested in comprehensive information about the potential of accessions. The availability of such information should be facilitated by the information systems once curation has been performed by the appropriate plant phenotyping standards (Papoutsoglou et al. 2020) and Ontologies (Shrestha et al. 2012). The use of proper accession numbers (such as the DOIs) enables data integration across studies in order to contribute efficiently to the conservation and sustainable use of crop diversity and benefit-sharing.

The numerous activities encompassing the ITC generate enormous potential for greater collaboration and knowledge exchange, which is where MusaNet plays its part. Stronger linkages among researchers of different disciplines and regions are being forged in order to develop projects and guidelines that result in positive and lasting impacts on banana production systems and livelihoods.

\section{Acknowledgements \\ We thank all the scientists and organizations who contributed to the invalu- able services and resources at the ITC, including KULeuven, University of Liege, Institute of Experimental Botany, L'Institut de recherche pour le développe- ment, and Botanic Garden of Meise. We are grateful to our national and regional partners, as well all MusaNet members.}

\section{Authors' contributions}

NR gathered information for the introduction of the paper. IVdH provided information on collection holdings, MTS, material distribution. BP provided information on cryopreservation and seed bank. SM provided information on virus indexing. JS provided information on molecular characterization, gap analyses and collecting missions. RC provided information on field verification, networking, abstract, conclusion and editing. SC provided information on phenotyping and evaluation. MRo provided information on genebank genomics and information systems. MRu, EK and VG provided information on information systems. All authors read and approved the final manuscript.

\section{Funding}

The authors thank all donors who supported this work through their contributions to the CGIAR Fund, in particular to the CGIAR Genebank Platform, coordinated by the Global Diversity Crop Trust, and the CGIAR Research Program, Roots, Tubers and Bananas (RTB). Authors want also to acknowledge regular support the Directorate-general Development Cooperation (DGD) and Humanitarian Aid from the Belgian Development Cooperation, the German Agency for International Development (GIZ) and the research and innovation Partnership on Food and nutrition security and sustainable agriculture LEAPAGRI. Finally, grants which significantly supported the work described in the review. The phenotyping work was undertaken with support of the initiative "Adapting Agriculture to Climate Change: Collecting, Protecting and Preparing Crop Wild Relatives" which is supported by the Government of Norway, the DGD project "More fruit for food security: developing climate-smart bananas for the African Great Lakes region", the project "Phenotyping the banana biodiversity to identify climate smart varieties with optimal market potential in Africa and Europe" (FWO-Flanders) and the European Union's Horizon 2020 Research and Innovation Programme (EPPN2020: Grant Agreement: 731013) Bananadyn EPPN2020. The seed conservation work was funded as a subgrant from the University of Queensland from the Bill \& Melinda Gates Foundation project 'BBTV mitigation: Community management in Nigeria, and screening wild banana progenitors for resistance' [OPP1130226].

\section{Availability of data and materials}

Not applicable.

Ethics approval and consent to participate

Not applicable.

\section{Consent for publication}

Not applicable.

\section{Competing interests}

The authors declare that they have no competing interests.

\section{Author details}

${ }^{1}$ Bioversity International, Willem De Croylaan 42, 3001 Leuven, Belgium. ${ }^{2}$ Bioversity International, Parc Scientifique Agropolis II, 34397 Montpellier, France. 
${ }^{3}$ Laboratory of Tropical Crop Improvement, Division of Crop Biotechnics, KU Leuven, B-3001 Leuven, Belgium. ${ }^{4}$ Integrated and Urban Plant Pathology Laboratory, Gembloux Agro-Bio Tech (GxABT), University of Liège, 5030 Gembloux, Belgium.

Received: 15 July 2020 Accepted: 5 October 2020 Published online: 22 October 2020

\section{References}

Acker JP, Adkins S, Alves ASV, Horna D, Toll J. Feasibility study for a safety backup cryopreservation facility. Independent expert report; 2017.

Adheka JG, Dhed'a, D.B., Karamura, D., Blomme, G., Swennen, R. and De Langhe, E. The morphological diversity of plantain in the Democratic Republic of Congo. Sci Hortic. 2018;234:126-33.

Alercia A, Diulgheroff S, Mackay M, et al.FAO/bioversity multi-crop passport descriptors V. 2.1 [MCPD V. 2.1]-December 2015, Bioversity International; 2015.

Al-Idrus A, Carpentier SC, Ahmad MT, Panis B, Mohamed Z. Elucidation of the compatible interaction between banana and Meloidogyne incognita via high-throughput proteome profiling. PLoS ONE. 2017;12:e0178438.

Arnaud E, Horry J-P.Musalogue: a catalogue of Musa germplasm-Papua New Guinea collecting missions 1988-1989, Bioversity International; 1997.

Baurens F-C, Martin G, Hervouet C, et al. Recombination and large structural variations shape interspecific edible bananas genomes. Mol Biol Evol. 2019;36:97-111.

Bawin Y, Panis B, Abeele SV, et al. Genetic diversity and core subset selection in ex situ seed collections of the banana crop wild relative Musa balbisiana. Plant Genetic Resourc. 2019;17:536-44.

Belser C, Istace B, Denis E, et al. Chromosome-scale assemblies of plant genomes using nanopore long reads and optical maps. Nature Plants. 2018;4:879.

Boonruangrod R, Fluch S, Burg K. Elucidation of origin of the present day hybrid banana cultivars using the $5^{\prime}$ ETS rDNA sequence information. Mol Breeding. 2009;24:77-91.

Brink M, van Hintum T. Genebank Operation in the Arena of Access and Benefit-Sharing Policies. Front. Plant Sci. 2020;10:1. https://doi.org/10.3389/ fpls.2019.01712.

Byabachwezi MSR, Mkulila S, Karamura DA.Tanzania Musa expedition 2005: Morogoro-Mbeva region, December 2005, INIBAP; 2005.

Castañeda-Álvarez NP, Khoury CK, Achicanoy HA, et al. Global conservation priorities for crop wild relatives. Nature Plants. 2016;2:1-6.

Cenci A, Hueber Y, Zorrilla-Fontanesi Y, et al. Effect of paleopolyploidy and allopolyploidy on gene expression in banana. BMC Genomics. 2019:20:244.

Cenci A, Sardos J, Hueber Y, Martin G, Breton C, Roux N, Swennen R, Carpentier SC, Rouard M. Unravelling the complex story of intergenomic recombination in ABB allotriploid bananas. Ann Bot. 2020. https://doi. org/10.1093/aob/mcaa032/5760888.

Chabannes M, Baurens F-C, Duroy P-O, Bocs S, Vernerey M-S, Rodier-Goud M, Barbe V, Gayral P, Iskra-Caruana M-L. Three Infectious Viral Species Lying in Wait in the Banana Genome. J. Virol. 2013:87(15):8624-37.

Chase R, Sardos J, Ruas M, Van den Houwe I, Roux N, Hribova E, Dolezel J. The field verification activity: a cooperative approach to the management of the global Musa in vitro collection at the International Transit Centre. In XXIX International Horticultural Congress on Horticulture: Sustaining Lives, Livelihoods and Landscapes (IHC2014): IX 1114. 2014; pp. 61-66.

Chin H. Germination and storage of banana seeds. In: Horry JP, De Waele D, editors. New Frontiers in Resistance Breeding for Nematodes, Fusarium and Sigatoka EA Frison. France: INIBAP, Montpellier; 1996. p. 218-227.

Christelová P, Langhe ED, Hřibová E, et al. Molecular and cytological characterization of the global Musa germplasm collection provides insights into the treasure of banana diversity. Biodivers Conserv. 2017;26:801-24.

Christelová P, Valarik M, Hribova E, Van den houwe I, Channeliere S, Roux N, Dolezel J. A platform for efficient genotyping in Musa using microsatellite markers. AoB Plants, 2011; plr024-plr024.

Čížková J, Hřibová E, Christelová P, Van den Houwe I, Häkkinen M, Roux N, Swennen R, Doležel J. Molecular and cytogenetic characterization of wild musa species. PLoS ONE. 2015;10:e0134096.
Cote F, Goue O, Domergue R, Panis B, Jenny C. In-field behaviour of banana plants (Musa AA sp) obtained after regeneration of cryopreserved embryogenic cell suspensions. Cryo Letters. 2000;21:19-24.

Davey JW, Davey JL, Blaxter ML, Blaxter MW. RADSeq: next-generation population genetics. Brief Funct Genomics. 2010;9:416-23.

Davey MW, Gudimella R, Harikrishna JA, Sin LW, Khalid N, Keulemans J. A draft Musa balbisiana genome sequence for molecular genetics in polyploid, inter- and intra-specific Musa hybrids. BMC Genomics. 2013;14:683.

De Clerck C, Crew K, Van den Houwe I, et al. Lessons learned from the virus indexing of Musa germplasm: insights from a multiyear collaboration. Ann Appl Biol. 2017;171(1):15-27.

De Langhe E, Karamura D, Mbwana A. Tanzania Musa Expedition 2001. Rome: INIBAP/IPGRI, Future Harvest; 2001.

De Langhe, E. de, Laliberte, B., Chase, R., et al. (2018) The 2016 Global Strategy for the conservation and use of Musa genetic resources - key strategic elements. Acta Horticulturae, 71-78.

D'Hont A, Denoeud F, Aury J-M, et al. The banana (Musa acuminata) genome and the evolution of monocotyledonous plants. Nature. 2012;488:213

Drapal M, Amah D, Schöny H, Brown A, Swennen R, Fraser PD. Assessment of metabolic variability and diversity present in leaf, peel and pulp tissue of diploid and triploid Musa spp. Phytochemistry. 2020;176:112388.

Drapal M, de Carvalho EB, Rouard M, et al. Metabolite profiling characterises chemotypes of Musa diploids and triploids at juvenile and pre-flowering growth stages. Sci Rep. 2019;9:4657.

Droc, G., Lariviere, D., Guignon, V., et al.(2013) The Banana Genome Hub. Database, 2013, bat035-bat035.

Dupouy M, Baurens F-C, Derouault P, et al. Two large reciprocal translocations characterized in the disease resistance-rich burmannica genetic group of Musa acuminata. Ann. Bot. 2019;124(2):319-29.

Dussert S, Engelmann F, Noirot M. Development of probabilistic tools to assist in the establishment and management of cryopreserved plant germplasm collections. Cryo Lett. 2003;24:149-60.

Elshire RJ, Glaubitz JC, Sun Q, Poland JA, Kawamoto K, Buckler ES, Mitchell SE. A robust, simple genotyping-by-sequencing (GBS) approach for high diversity species. PLoS ONE. 2011;6:e19379.

Ficklin, S.P., Sanderson, L.-A., Cheng, C.-H., Staton, M.E., Lee, T., Cho, I.-H., Jung, S., Bett, K.E. and Main, D. (2011) Tripal: a construction toolkit for online genome databases. Database (Oxford), 2011.

Foley JA, Ramankutty N, Brauman KA, et al. Solutions for a cultivated planet. Nature. 2011;478:337-42.

Gallez A, Runyoro G, Mbehoma CB, van den Houwe I, Swennen R. Rapid mass propagation and diffusion of new banana varieties among small-scale farmers in north western Tanzania. Afr Crop Sci J. 2004;12:7-17.

Galluzzi G, Halewood M, Noriega I, Vernooy R. Twenty-five years of international exchanges of plant genetic resources facilitated by the CGIAR genebanks: a case study on global interdependence. Biodivers Conserv. 2016;25:1421-46.

Garming H, Roux N, Houwe I. The impact of the Musa International Transit Centre: review of its services and cost-effectiveness, and recommendations for rationalization of its operations; 2010.

Ghosh S, Watson A, Gonzalez-Navarro OE, et al. Speed breeding in growth chambers and glasshouses for crop breeding and model plant research. Nat Protoc. 2018;13:2944-63.

Gibbs D, Turner D. A functional approach to bunch formation in banana. In Achieving sustainable cultivation of bananas. Burleigh Dodds Science Publishing, 2013; pp. 113-136.

Giovannini P, Major M, Roux M, Sardos J. Banana diversity in the CGIAR collection: finding and filling the gaps (Poster presented at a side event of the Eighth Session of the Governing Body of International Treaty on Plant Genetic Resources for Food and Agriculture); 2019. Retrieved 12 June 2020 from https://www.genebanks.org/wp-content/uploads/2019/11/ Banana-Diversity-Tree-Poster.pdf.

Halewood M, Lopez Noriega I, Ellis D, Roa C, Rouard M, Sackville Hamilton N. Potential implications of the use of digital sequence information on genetic resources for the three objectives of the Convention on Biological Diversity. A submission from CGIAR to the Secretary of the Convention on Biological Diversity (CBD); 2017.

Helliot B, Panis B, Poumay Y, Swennen R, Lepoivre P, Frison E. Cryopreservation for the elimination of cucumber mosaic and banana streak viruses from banana (Musa spp.). Plant Cell Rep. 2002;20:1117-22. 
van Hintum T, Menting F, van Strien E. Quality indicators for passport data in ex situ genebanks. Plant Genetic Resourc. 2011a;9:478-85.

Irish BM, Cuevas HE, Simpson SA, Scheffler BE, Sardos J, Ploetz R, Goenaga R. (2014) spp. Germplasm Management: Microsatellite Fingerprinting of USDA-ARS National Plant Germplasm System Collection. Crop Science, 54,2140 .

Iskra-Caruana M-L, Chabannes M, Duroy P-O, Muller E. A possible scenario for the evolution of Banana streak virus in banana. Virus Res. 2014:186:155-62.

Jamil IN, Remali J, Azizan KA, Nor Muhammad NA, Arita M, Goh H-H, Aizat WM. Systematic Multi-Omics Integration (MOl) Approach in Plant Systems Biology. Front. Plant Sci. 2020;11:944.

Janssens SB, Vandelook F, De Langhe E, Verstraete B, Smets E, Vandenhouwe I, Swennen R. Evolutionary dynamics and biogeography of Musaceae reveal a correlation between the diversification of the banana family and the geological and climatic history of Southeast Asia. New Phytol. 2016;210:1453-65.

Kamira M, Ntamwira J, Sivirihauma C, Ocimati W, van Asten P, Vutseme L, Blomme G. Agronomic performance of local and introduced plantains, dessert, cooking and beer bananas (Musa spp.) across different altitude and soil conditions in eastern Democratic Republic of Congo. AJAR. 2016;11:4313-32.

Kehel, Z., Crossa, J. and Reynolds, M. (2016) Identifying Climate Patterns during the Crop-Growing Cycle from 30 Years of CIMMYT Elite Spring Wheat International Yield Trials. Applied mathematics and omics to assess crop genetic resources for climate change adaptive traits, 151-174.

Keller E, Senula A, Grübe M, Diekmann K, Dehmer K. Fifteen years of cryopreservation in the IPK Genebank-experience, conclusions and outlook. II International Symposium on Plant Cryopreservation. 2013;1039:249-63.

Kilian B, Graner A. NGS technologies for analyzing germplasm diversity in genebanks. Brief Funct Genom. 2012;11:38-50.

Kissel E, Vanhove AC, Garcia S, et al. Abiotic stress research in crops using -omics approaches: drought stress and banana in the spotlight. Acta Horticulturae. 2016; 81-90

Lassois L, Lepoivre P, Swennen R, van den Houwe I, Panis B. Thermotherapy, chemotherapy, and meristem culture in banana. Methods Mol Biol. 2013;11013:419-33.

Li L-F, Häkkinen M, Yuan Y-M, Hao G, Ge X-J. Molecular phylogeny and systematics of the banana family (Musaceae) inferred from multiple nuclear and chloroplast DNA fragments, with a special reference to the genus Musa. Mol Phylogenet Evol. 2010;57:1-10.

Machovina B, Feeley KJ. Climate change driven shifts in the extent and location of areas suitable for export banana production. Ecol Econ. 2013;95:83-95.

Martin G, Baurens F-C, Droc G, et al. Improvement of the banana "Musa acuminata" reference sequence using NGS data and semi-automated bioinformatics methods. BMC Genomics. 2016;17:243.

Martin G, Cardi C, Sarah G, Ricci S, Jenny C, Fondi E, Perrier X, Glaszmann J-C, D'Hont A, Yahiaoui N. Genome ancestry mosaics reveal multiple and cryptic contributors to cultivated banana. Plant J. 2020;102(5):1008-25.

Mascher, M., Schreiber, M., Scholz, U., Graner, A., Reif, J.C. and Stein, N. Genebank genomics bridges the gap between the conservation of crop diversity and plant breeding. Nat Genet. 2019;51:1076-81.

Massart S, Candresse T, Gil J, et al. A framework for the evaluation of biosecurity, commercial, regulatory, and scientific impacts of plant viruses and viroids identified by NGS Technologies. Front. Microbiol. 2017;8:1.

McCouch SR, McNally KL, Wang W, Hamilton RS. Genomics of gene banks: A case study in rice. Am J Bot. 2012;99:407-23.

MusaNet (2012) Trust joint meeting report on the Effective Use of Genetic Diversity for Addressing Emerging Challenges in Banana and Plantain Breeding, Bogor, Indonesia.

MusaNet and Laliberte, B. (2016) Global strategy for the conservation and use of Musa genetic resources, Bioversity International. 2016. https://cgspace. cgiar.org/handle/10568/77332. Accessed 1 July 2020.

Ocimati W, Blomme G, Rutikanga A, Ragama P, Gaidashova S, Nsabimana A Murekezi C. Musa germplasm diversity status across a wide range of agro-ecological zones in Rwanda. J Appl Biosci. 2014;73:5979-90.

Oh TJ, Cullis MA, Kunert K, Engelborghs I, Swennen R, Cullis CA. Genomic changes associated with somaclonal variation in banana (Musa spp.). Physiol Plant. 2007;129:766-74.
Olmos A, Boonham N, Candresse T, et al. High-throughput sequencing technologies for plant pest diagnosis: challenges and opportunities. EPPO Bulletin. 2018;48:219-24.

Panis B. Sixty years of plant cryopreservation: From freezing Hardy mulberry twigs to establishing reference crop collections for future generations. Acta Hort. 2019;1234:1-8.

Panis, B., Piette, B., André, E., Van den houwe, I. and Swennen, R. (2011) Droplet vitrification: the first generic cryopreservation protocol for organized plant tissues? In Acta Horticulturae. International Society for Horticultural Science (ISHS), Leuven, Belgium, pp. 157-162. https://doi. org/https://doi.org/10.17660/ActaHortic.2011.908.17.

Panis B, Piette B, Swennen R. Droplet vitrification of apical meristems: a cryopreservation protocol applicable to all Musaceae. Plant Sci. 2005;168:45-55.

Panis B, Totté N, Van Nimmen K, Withers LA, Swennen R. Cryopreservation of banana (Musa spp.) meristem cultures after preculture on sucrose. Plant Sci. 1996;121:95-106.

Panis B, Withers L, De Langhe E. Cryopreservation of Musa suspension cultures and subsequent regeneration of plants. CryoLetters. 1990;11:337-50.

Papoutsoglou EA, Faria D, Arend D, et al. Enabling reusability of plant phenomic datasets with MIAPPE 1.1. New Phytol. 2020;227:260-73.

Passos MAN, de Cruz VO, Emediato FL, et al. Analysis of the leaf transcriptome of Musa acuminata during interaction with Mycosphaerella musicola: gene assembly, annotation and marker development. BMC Genomics. 2013;14:78

Quatrano RS. Freeze-Preservation of Cultured Flax Cells Utilizing Dimethyl Sulfoxide. Plant Physiol. 1968;43:2057-61.

Rippke U, Ramirez-Villegas J, Jarvis A, Vermeulen SJ, Parker L, Mer F, Diekkrüger B, Challinor AJ, Howden M. Timescales of transformational climate change adaptation in sub-Saharan African agriculture. Nature Climate Change. 2016;6:605-9.

Rosales F, Arnaud E, Coto J. A tribute to the work of Paul Allen. INIBAP, Montpellier, France: A catalogue of wild and cultivated bananas; 1999.

Rouard M, Droc G, Martin G, et al. Three new genome assemblies support a rapid radiation in Musa acuminata (wild banana). Genome Biol Evol. 2019;10(12):3129-40.

Rouard, M., Guignon, V., Lehrer, K., Ruas, M., Sardos, J. and Roux, N. (2018) Literature tracking use of Musa accessions at Bioversity International Musa Germplasm Transit Centre (2007-2018). https://dataverse.harvard. edu/citation?persistentld=doi:https://doi.org/10.7910/DVN/031C4P. Accessed 15 June 2020].

Ruas, M., Guignon, V., Sempere, G., et al. (2017) MGIS: managing banana (Musa spp.) genetic resources information and high-throughput genotyping data. Database (Oxford), 2017.

Sanderson L-A, Ficklin SP, Cheng C-H, Jung S, Feltus FA, Bett KE, Main D. Tripal V1.1: a standards-based toolkit for construction of online genetic and genomic databases. Database, 2013, bat075-bat075.

Sardos J, Christelová P, Čížková J, et al. Collection of new diversity of wild and cultivated bananas (Musa spp.) in the Autonomous Region of Bougainville, Papua New Guinea. Genet Resour Crop Evol. 2018;65:2267-86.

Sardos J, Paofa J, Janssens S, Sachter-Smith G, Rauka G, Roux N.Banana collecting mission in the Autonomous Region of Bougainville (AROB), Papua New Guinea., 2017. https://cgspace.cgiar.org/handle/10568/83229. Accessed 1 July 2020

Sardos J, Perrier X, Doležel J, Hřibová E, Christelová P, den Houwe IV, Kilian A, Roux N. DArT whole genome profiling provides insights on the evolution and taxonomy of edible Banana (Musa spp.). Ann Bot. 2016:118:1269-78.

Sardos J, Rouard M, Hueber Y, Cenci A, Hyma KE, van den Houwe I, Hribova E, Courtois B, Roux N. A Genome-Wide Association Study on the Seedless Phenotype in Banana (Musa spp) Reveals the Potential of a Selected Panel to Detect Candidate Genes in a Vegetatively Propagated Crop. PLOS ONE. 2016;1 1:e0154448.

Sardos J, Sachter-Smith G, Ghanem M, Hribova E, van Den Houwe I, Roux N, Wigmore W.Report from the Banana Collecting Mission to Rarotonga and Aitutaki, Cook Islands. 2019. https://drive.google.com/file/d/1YYg-qBXBP CCXSR5qcogzeCXer74ymndJ/view.

Sardos J, Sachter-Smith G, Shandil A, et al.Report from the Banana Collecting Mission to Samoa, 2019. https://drive.google.com/file/d/109BOdL08c X2aPOHJWCJtt88MXnOUtIPn/view. 
Selby P, Abbeloos R, Backlund JE, et al. BrAPI—an application programming interface for plant breeding applications. Bioinformatics. 2019:35:4147-55.

Sempéré G, Pétel A, Rouard M, Frouin J, Hueber Y, De Bellis F, Larmande P. Gigwa v2 - Extended and improved genotype investigator. Gigascience. 2019. https://academic.oup.com/gigascience/article/8/5/giz051/54881 03. Accessed 16 May 2019.

Sharrock S.Report on the first IBPGR-QDPI banana germplasm collecting mission to Papua New Guinea, 27 February to 22 March 1988, IBPGR.

Sharrock S.Report on the fourth IBPGR-QDPI banana germplasm collecting mission to Papua New Guinea, 4 June to 9 July 1989, IBPGR; 1989.

Sharrock S, Daniells JW, Kambuou R, IBPGR. Report on the second IBPGR-QDPI banana germplasm collecting mission to Papua New Guinea, 22 October to 27 November 1988, IBPGR; 1988.

Sharrock S, Jones DR, Banag J, IBPGR.Report on the third IBPGR-QDPI banana germplasm collecting mission to Papua New Guinea, 15 February to 12 March 1989, IBPGR; 1989.

Shrestha R, Matteis L, Skofic M, Portugal A, McLaren G, Hyman G, Arnaud E. Bridging the phenotypic and genetic data useful for integrated breeding through a data annotation using the Crop Ontology developed by the crop communities of practice. Front Physiol. 2012;3:1.

Simmonds NW. A banana collecting expedition to South East Asia and the Pacific; 1956.

Simmonds NW. The germination of banana seeds; 1952.

Spooner D.Molecular markers for genebank management, Bioversity International; 2005.

Stotzky G, Cox EA, Goos RD. Seed germination studies in Musa. I. Scarification and aseptic germination of Musa balbisiana. Am J Bot. 1962;49:515-20.

Tarafdar S, Gupta K, Banerjee S, Shailja D. Identification of SSR \& ISSR Markers Associated to Off-Type Somaclonal Variants in Micro-Propagated Banana; 2017.

Taxonomy Advisory Group (TAG). Guidelines for taking the minimum set of photos; 2010.

Taxonomy Advisory Group (TAG) (2016) Minimum List of Descriptors for Musa. https://drive.google.com/file/d/1WS_nL_FmgVYFfZMRgSdR03EbNa Cp_IFa/view? usp=sharing.

Thinh N, Takagi H, Yashima S. Cryopreservation of in vitro-grown shoot tips of banana (Musa spp) by vitrification method. Cryo-Lett. 1999;20:163-74.

Thomas JE, Sharman M, Lassois L, et al. Technical guidelines for the safe movement of Musa germplasm; 2015.

Timm ES, Pardo LH, Coello RP, Navarrete TC, Villegas ON, Ordóñez ES. Identification of differentially-expressed genes in response to Mycosphaerella fijiensis in the Resistant Musa Accession 'Calcutta-4' Using Suppression Subtractive Hybridization. PLoS ONE. 2016;11:e0160083.
Turner DW, Fortescue JA, Ocimati W, Blomme G. Plantain cultivars (Musa spp. $A A B$ ) grown at different altitudes demonstrate cool temperature and photoperiod responses relevant to genetic improvement. Field Crops Research. 2016;194:103-11.

Turner NC. Plant water relations and irrigation management. Agric Water Manag. 1990;17:59-73.

Van den houwe, I., De Smet, K., Montcel, H.T. du and Swennen, R. Variability in storage potential of banana shoot cultures under medium term storage conditions. Plant Cell Tiss Organ Cult. 1995;42:269-74.

Van den houwe I, Swennen R. Characterization and control of bacterial contaminants in in vitro cultures of banana (Musa spp.). International Symposium on Methods and Markers for Quality Assurance in Micropropagation. 1999;530:69-79.

Van der Veken L, Win PP, Massart A, Elsen A, Swennen R, De Waele D. Autotropic in vitro model system for the in-depth study between nematodes and Rhizobium spp. Commun Agric Appl Biol Sci. 2007;72:651-3.

Wang W, Mauleon R, Hu Z, et al. Genomic variation in 3,010 diverse accessions of Asian cultivated rice. Nature. 2018;1:1.

Wang Z, Miao H, Liu J, et al. Musa balbisiana genome reveals subgenome evolution and functional divergence. Nature Plants. 2019;1:1.

Wesemael J, Hueber Y, Kissel E, Campos N, Swennen R, Carpentier S. Homeolog expression analysis in an allotriploid non-model crop via integration of transcriptomics and proteomics. Scientific Reports. 2018;8:1353.

Wheeler T, Von Braun J. Climate change impacts on global food security. Science. 2013;341:508-13.

Zhang L, Cenci A, Rouard M, Zhang D, Wang Y, Tang W, Zheng S-J. Transcriptomic analysis of resistant and susceptible banana corms in response to infection by Fusarium oxysporum f. sp. cubense tropical race 4. Sci Reports. 2019;9:8199.

Zivy M, Wienkoop S, Renaut J, Pinheiro C, Goulas E, Carpentier S. The quest for tolerant varieties: the importance of integrating "omics" techniques to phenotyping. Front. Plant Sci. 2015. https://doi.org/10.3389/ fpls.2015.00448/full.

Zorrilla-Fontanesi Y, Rouard M, Cenci A, et al. Differential root transcriptomics in a polyploid non-model crop: the importance of respiration during osmotic stress. Sci Rep. 2016;6:22583.

\section{Publisher's Note}

Springer Nature remains neutral with regard to jurisdictional claims in published maps and institutional affiliations.
Ready to submit your research? Choose BMC and benefit from:

- fast, convenient online submission

- thorough peer review by experienced researchers in your field

- rapid publication on acceptance

- support for research data, including large and complex data types

- gold Open Access which fosters wider collaboration and increased citations

- maximum visibility for your research: over $100 \mathrm{M}$ website views per year

At $\mathrm{BMC}$, research is always in progress.

Learn more biomedcentral.com/submissions 